\title{
A two-stage residential location and transport mode choice model with exposure to traffic-induced air pollution
}

\author{
Mirjam Schindler $^{\mathrm{a}, *}$, Judith Y.T. Wang ${ }^{\mathrm{b}}$, Richard D. Connors ${ }^{\mathrm{c}}$ \\ ${ }^{\text {a }}$ School of Geography, Environment and Earth Sciences, Victoria University of Wellington, New Zealand \\ ${ }^{\mathrm{b}}$ School of Civil Engineering and Institute for Transport Studies, University of Leeds, Leeds, United Kingdom \\ ${ }^{\mathrm{c}}$ Institute for Transport Studies, University of Leeds, United Kingdom and Faculté des Sciences des Technologies et de Médecine, University of Luxembourg, Luxembourg
}

\section{A R T I C L E I N F O}

\section{Keywords:}

Localised air pollution

Urban structure

Transport mode choice

Residential location choice

Traffic-induced air pollution

\begin{abstract}
A B S T R A C T
Air pollution is an increasing concern to urban residents. In response, residents are beginning to adapt their travel behaviour and to consider local air quality when choosing a home. We study implications of such behaviour for the morphology of cities and population exposure to traffic-induced air pollution. To do so, we propose a spatially explicit and integrated residential location and transport mode choice model for a city with traffic-induced air pollution. Intra-urban spatial patterns of population densities, transport mode choices, and resulting population exposure are analysed for urban settings of varying levels of health concern and air pollution information available to residents. Numerical analysis of the feedback between residential location choice and transport mode choice, and between residents' choices and the subsequent potential impact on their own health suggests that increased availability of information on spatially variable traffic-induced health concerns shifts population towards suburban areas with availability of public transport. Thus, health benefits result from reduced population densities close to urban centres in this context. To mitigate population exposure, our work highlights the need for spatially explicit information on peoples' air pollution concerns and, on this basis, spatially differentiated integrated land use and transport measures.
\end{abstract}

\section{Introduction}

\subsection{Urbanisation, air quality and health}

The phenomenon of urbanisation is observed around the world in both developing and developed countries. The motivation of migration or relocation of residence is to seek a better life, whether from rural areas to the city for a better income, or from the city central areas to suburbs for a better lifestyle. In most cases, it might bring wealth and/or improvement of quality of life. Nonetheless, changing residential location might incur costs that are initially less obvious. Over recent decades, it has become increasingly clear that urbanisation has a negative impact on the environment, which can have detrimental effects on population health. In particular, traffic congestion in many cities has become a major source of air pollution. The deterioration of air quality and its localised effect, affects not only residents of that vicinity but also those passing through on their journeys to work. The long term effects include premature mortality. Tackling the health impact of this phenomenon and managing its negative impact has become one of the biggest challenges we are facing in this century.

Extensive research effort has been devoted to improve and promote health and wellbeing of cities in recent years. In order to address the pertinent issues, one must look into the cause of the problems. Suboptimal urban and transport planning has been viewed as a plausible cause of the undesirable impact on public health (Nieuwenhuijsen, 2020). To a certain extent, this is not only the consequence of decisions made by the government through urban and transport planning, but also the choices made by all the city inhabitants. Their choices of where to live and work is a blueprint for the urban form of a city, and their residential location choices have most likely been made together with their transport choices. If we wish to promote healthier cities, urban and transport planning decisions must be made in view of such feedback mechanism. Miller (2018) highlights the importance of modelling this "feedback" effect of transport infrastructure investments on urban form, which must be considered in the evaluation and decision making process of policy decisions.

\footnotetext{
* Corresponding author.

E-mail address: mirjam.schindler@vuw.ac.nz (M. Schindler).
} 


\subsection{Integrated land-use transport modelling}

In recognition of the complexity of urban systems, an integrated approach has been adopted in urban and transport planning, known as Integrated Urban Models (IUMs), where transport and land-use models are integrated. This is a classical approach that has been applied and put into practice for over 50 years, developed based on robust utility/ discrete choice theory (Miller, 2018). As Miller reiterates in his latest review, 'If the world is to have any hope of achieving some form of economic, social and environmental sustainability then we must do a better job of integrating land use and transportation system design in holistic and comprehensive ways.' Miller (2018) also identifies some additional key policy questions that could benefit from an IUM approach, including: (1) air pollution impact; and (2) health impacts of land-use patterns and travel behaviour.

\subsection{Land-use, transport choices, air quality and health impact assessment}

Naturally, this integrated approach has extended beyond land-use and transport planning to model the policy impact on air quality and population health. To model such complex interactions, a fully integrated analysis might broadly involve four major modelling components:

1. Land-use planning: Location choice; urban form

2. Transport planning: Transport choice; traffic modelling

3. Air quality analysis: Vehicle emissions; pollutant dispersion \& concentrations

4. Health impact analysis: Pollutant exposure; health impact assessment

Depending on the purpose of a study, different combinations of selected components might be deployed. The integration between different components can be very complex in order to represent the complex interactive relationships between different systems. There are generally two kinds of models, namely, decision science and physical science models. Decision science models include: (1) Location choices made by businesses and residents modelled in land-use planning; and (2) Transport choices made by residents modelled in transport planning. As a result of their choices, the physical science of how vehicle emissions disperse into the atmosphere and impact on population health are modelled in air quality and health impact analyses. Pollutant exposure is a common theme in both air quality and health impact analyses, with air quality analysis focussing more on the environmental impact in terms of concentrations while health impact analysis focusses more on the spatial effect of the environment on population health.

Our objective in the present paper is to integrate all of these four major components, including both decision and physical science models, to support policy analysis specifically related to air quality and the potential health impacts of both land-use and transport planning. Our goal is to be able to model such effects spatially as well as at an individual decision level. While the physical science components have been well developed, their integration with the decision science components has either been missing or needing improvements. What we would like to achieve is to integrate decision and physical sciences with our proposed model to represent the complexity of urban systems more realistically. Before we introduce our model, we first look at how different combinations of components have been integrated in the literature and identify the knowledge gaps that need to be addressed.

\subsection{Linking transport planning \& air quality models}

The linkage of transport planning models to air quality analysis has the longest history in the literature and has been well developed both in theory and in practice. Numerous models have been motivated by clear evidence of air pollution caused by traffic congestion resulting from transport choices; and the need to assess policy analysis of road network scenarios or schemes such as congestion pricing, speed limits, freight corridors, road capacity changes, etc. on the environment (e.g. Baldasano et al., 2010; Boogaard et al., 2012; Briggs et al., 2008; Coria et al., 2015; Mitchell et al., 2005; Namdeo and Mitchell, 2008; Lee et al., 2009; Tennoy et al., 2019; You et al., 2010). The linkages between the model components are mainly based on physical sciences. The transport planning model provides traffic information on flow, speed and vehicle types on each roadway, to the vehicle emission model; pollutant concentrations can then be calculated based on the dispersion of vehicle emissions; hence population exposure to the pollutants can be estimated (Affum et al., 2003; Hatzopoulou and Miller, 2010).

\subsection{Linking transport planning, air quality models \& health impact assessment}

As the awareness of poor air quality is growing, its subsequent effect on health has raised even stronger concern in society (HEI, 2010; Boogaard et al., 2019). Empirical evidence from the last two decades has shown that the characteristics of city, land-use and transport planning are directly linked with air quality, pollutant exposure, level of physical activity and their possible combined health impact (e.g. de Nazelle et al., 2011, 2012; Dons et al., 2018, 2019; Oja et al., 2011; Shekarrizfard et al., 2015, 2020; Sider et al., 2013). Health impact assessment models are vital to facilitate policy analysis that can support healthier development of cities and our transportation systems. Promoting active modes of transport, including walking and cycling, and modal shifts from private vehicles to public transport, have been seen as the natural strategies to combat both the lack of physical activity and poor air quality (Nieuwenhuijsen, 2020; Sallis et al., 2016).

To support policy analysis, health impact assessment methods have been developed to find out what health benefit might be achievable under different scenarios. For instance, Woodcock et al. (2013) applied an Integrated Transport and Health Impact Modelling Tool (ITHIM), developed from the work in Woodcock et al. (2009), to quantify the health impacts from transport-related physical activity as well as changes to air pollution. Scenarios representing different visions of behavioural change are formulated and the health impacts are assessed with ITHIM (Woodcock et al., 2013). Models such as ITHIM focusses on the physical science of translating a given vision such as certain desirable level of reduction in traffic to its potential impact on health. Transport choices are not modelled but treated as visions. As pointed out in Wang and Connors (2018), a key assumption in ITHIM is that the reduction in road transport trips, as a result of increases in walking and cycling instead of car use, led to equal proportional reduction in pollutants attributed to transport. This assumption might not be realistic; it oversimplifies the relationship between traffic congestion and the resulting air pollution. In another study, Schepers et al. (2015) assess the potential health impact of investment in cycling infrastructure in a hypothetical city considering both the influence of changes in physical activity and pollutant dose. In this case, changes to mean concentrations are exogenously imposed for the health impact assessment. The effect of travel behavioural change in terms of modal shift from driving to cycling is not modelled. In general, health impact assessment models are not linked to travel behavioural models. Wang and Connors (2018) also emphasised the importance of modelling the localised effect of traffic on air quality and its subsequent effect on the vicinity for the residents as well as the pollutant dose during their journeys to work, depending on their mode choice. Wang and Connors (2018) are the first to model pollutant dose in this context.

\subsection{Linking urban form, transport planning \& air quality models}

The impact of urban form on air quality has been well recognised in the literature (e.g. Borrego et al., 2006; De Ridder et al., 2008a; Marshall et al., 2005; Martins, 2012; Schindler and Caruso, 2014). The subject of many studies is to look at what might be a better urban development strategy for a better environment; urban sprawl and compact 
development are often the two major strategies considered (e.g. Borrego et al., 2006; De Ridder et al., 2008b; Martins, 2012). For example, De Ridder et al. (2008a, 2008b) considered different levels of urban sprawl formulated as scenarios of development strategies. The classical transport planning model known as the four-stage model (Ortuzar and Willumsen, 2001) is embedded in the model to provide traffic information on speed, flow and density for the simulations. Residential location choices are not modelled but treated as a given level of sprawl in different scenarios. In other words, this assumes structures which are not derived from underlying urban processes. Only Schindler and Caruso (2014) have modelled the impact of urban form on air pollution and exposure, where urban form is based on residential location choices.

Empirical studies have shown that residents are concerned about air pollution exposure (Gatersleben and Uzzell, 2000) and indeed air quality and traffic conditions are two influential factors affecting residential location choices (Guo and Bhat, 2004). This might impact on urban form formation due to altered residential location choices. Thus, there is a feedback effect between urban form and pollution. Schindler et al. (2017) are the first to model how air quality might impact residential location choice in a linear city; Schindler and Caruso (2018) increased the spatial complexity of urban form to two dimensions. However, transport choices are not modelled as commute by car is assumed to be the only mode of transport (Schindler and Caruso, 2014; Schindler et al., 2017; Schindler and Caruso, 2018; Schindler and Caruso, 2021).

\subsection{Modelling the co-evolution of residential and transport choices with consideration of air quality and health impact}

As Nieuwenhuijsen (2020) illustrated in the health impact assessment framework, we will need both urban design and behavioural change to create pathways to healthier cities. To ensure the design of policies will give us pathways to success, one must understand the coevolution of land-use and transport as a result of behavioural change over time. Behavioural change is, to a certain extent, the pathway to success. With growing concern of poor air quality and its impact on health, there is a need to investigate how such concern might impact on residential location choice and subsequently on urban form, traffic, air quality and health. Our research questions are:

1. If residents are concerned about the health impact of air quality, how would this impact on their residential location choice?

2. How would their residential and transport choices impact on their own health and the health of others?

3. How would the urban form co-evolve with transport choices?

4. How would the air quality and health impacts co-evolve with the urban form and transport choices?

Question 1 has been addressed by (Schindler et al., 2017; Schindler and Caruso, 2021), while Question 2 has been partially addressed by Wang and Connors (2018). In this paper, we are addressing Questions 1 and 2 together, and making the first step for Questions 3 and 4. The key contribution of this paper is, therefore, on modelling the feedback between choices as well as the interaction of residents' choices with the environment and their own health.

To model behavioural change, we will need explicit linkages between decision and physical sciences to model all of the following:

1. the trade-offs faced by residents who have a portfolio of desires and concerns;

2. the feedback between residential location, transport choices and congestion; and

3. the feedback between the residents' choices and the subsequent impact on their own health.

We propose a joint urban-transport equilibrium model to help understand what the urban form and transport choices might be at one point in time as a result of the interactions. This is the first step to help understand how the urban form might co-evolve with transport choices in the future.

\section{The model}

\subsection{An overview of the two-stage game theoretical model}

Our model must capture the feedback in the decision making process between the longer-term residential location choice and day-to-day transport choices. In order to do so, we propose a two-stage game theoretical approach to model this process in a bi-modal linear monocentric city (LMC) as in Wang and Connors (2018) depicted in Fig. 1, where residents are distributed continuously along the city. Two modes of transport, rail and private vehicles, are available from any point along the city to a common destination, the Central Business District (CBD), represented by one end of the city. Residents will walk or cycle to the nearest station if they choose to take the train. Residents living close to the station, typically within $1 \mathrm{~km}$, will walk, while those living a bit further away (say within $5 \mathrm{~km}$ ) will cycle. There is also the alternative to walk/cycle directly to the CBD, without using train or car. If they choose to drive, they will join the highway at the location of their residence.

The first stage of the game represents the longer-term residential location choice, which can be at any point along the city, while the second stage represents the day-to-day transport choices, which is the mode choice between rail and driving. This two-stage game theory based decision process is depicted in Fig. 2.

\subsubsection{Stage-1 Residential location choice}

At any time, residents might consider to move or stay where they are. Their objective is always to maximise the aggregate utility associated with living at the selected location. In other words, they will move only if they can find another location with a higher aggregate utility of living there. The factors affecting this aggregate utility include: consumption of housing space and composite (non-housing) good, generalised transport cost for commute, health impact at residence and during commute. An urban equilibrium is reached when no one can improve the utility of their residential location choice by unilaterally moving to another location given the choices of all other residents.

\subsubsection{Stage-2 Transport mode choice}

Wang and Connors (2018) propose a multi-objective approach to model the transport equilibrium, i.e. a bi-modal three-objective user equilibrium (TUE) model, based on the simultaneous consideration of three objectives: (1) minimise travel time; (2) maximise travel time reliability; and (3) minimise monetary cost. When faced with the two alternatives, car or train, a user will consider the monetary cost alongside the departure time at which they will need to leave in order to achieve their desired arrival time reliability. The equilibrium principle behind TUE is that no user can improve any one of the three objectives without sacrificing the other two objectives, given the choices of all other users. At each location, the equilibrium modal split can be all different and it will follow this equilibrium condition. There are three possible outcomes: (1) all residents from this location will use rail; (2) all residents from this location will use car; and (3) some residents will use rail and some will use car. For details of the mathematical formulation of this TUE model, please refer to Wang and Connors (2018).

\subsubsection{Residential location \& transport mode choices and pollutant dose analysis}

In order to perform transport mode choice and air quality analysis, we need to start with the distribution of origins and destinations. In this case, we have only one destination (i.e. work in the CBD) and the distribution of origins depends on residential location choices. Given the distribution of residents' locations, Wang and Connors (2018)'s TUE model is effectively a spatial model of all transport choices made by each resident along the corridor. It enables not only the analysis of localised effect of their transport choices at each location, but also the effect on each resident's pollutant dose during their journey to work. Once the transport choices of each resident at different locations are determined, 


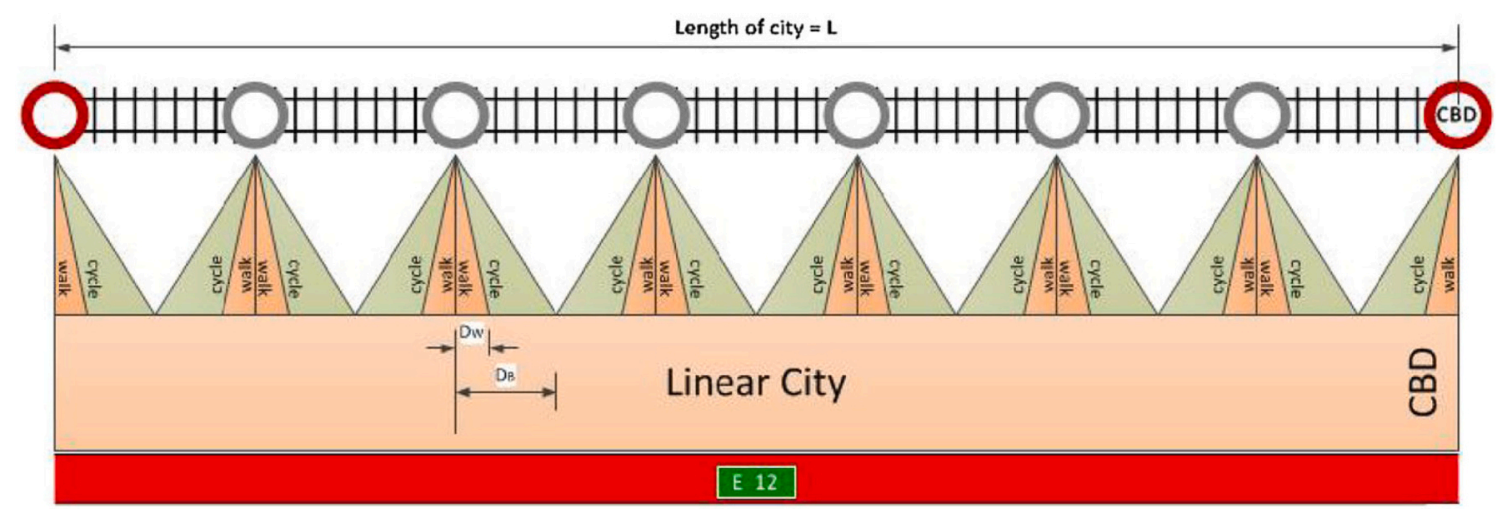

Fig. 1. A schematic design of a linear monocentric city as considered in this work, taken from Wang and Connors (2018).

vehicle emissions along the city can be predicted. Followed by applying a pollutant dispersion model, pollutant concentration level at each residential location can be calculated. Based on the concentration distribution, each resident's mode choice, the travel time on each leg of their journey to work, and the pollutant dose during commute can be calculated. The estimates of the pollutant dose at the residence and the pollutant dose during commute can now become the proxy variables measuring the potential health impact of each resident's location choice as well as their transport choices. Together with the residential location choices made throughout the city, we can then determine the spatial distribution of both doses as a result of each resident's choices. This pollutant dose analysis process is illustrated in Fig. 2.

\subsubsection{Joint urban-transport equilibrium}

When both the urban equilibrium and transport equilibrium conditions are met, there will be no incentive for any resident to move to a different location or change their mode choice. In other words, a joint urban-transport equilibrium is achieved when the two following conditions are met:

1. Urban equilibrium - No one can improve the utility of their residential location choice by unilaterally moving to another location given the location choices of all other residents; and

2. Transport equilibrium - No one can improve any one of the three criteria: (1) travel time; (2) travel time reliability; or (3) monetary cost without sacrificing any of the other two criteria by unilaterally changing their mode choice given the transport choices of all other residents.

\subsection{The modelling components}

From our literature review, it appears that air quality is one of the influential factors affecting residential location choice while transport policies such as congestion pricing, speed limits, etc. are policy instruments to induce behavioural change that affects air quality and its subsequent impact on health. Therefore, we postulate that pollutant doses at residence and during commute are factors affecting residential location choice. The assumption is that doses at residence and during commute are proxy variables representing the perceived impact on health of the combined lifestyle choice of where to live and how to travel; how they travel is determined based on the three most important objectives identified in the transport planning literature, namely, travel time, travel time reliability and monetary cost. Pollutant doses are determined based on the combined residential location and transport choices throughout the city. Details of the model components, the input and output of each component, and the linkages between them are explained as follows and visualised in Fig. 3.

\subsubsection{Residential location choice model}

Population distribution is endogenous and modelled based on resi- dential location choices of identical households. Households derive utility from consuming housing space and a composite good, but disutility from exposure at their residential location and during the commuting journey:

$U=\kappa Z(r)^{1-\alpha} H(r)^{\alpha} E_{R}(r)^{-\beta} E_{C}(r)^{-\gamma}$

$H(r)$ is the consumption of housing space as a function of the distance to the centre $r$, with population density at $r$ normalised to $1 / H(r) . Z(r)$ is the consumption of the composite good (non-housing). Every household is exposed to a level $E_{R}(r)$ at the residential location and to a pollutant dose level $E_{C}(r)$ during the commuting journey. Households value housing space by $\alpha$ but dislike being exposed to localised pollution at the residential local by $\beta$ and during the commuting journey by $\gamma$. $\kappa \equiv(1-$ $\alpha)^{\alpha-1} \alpha^{-\alpha}$ is a simplification constant used for convenience. Hence, Eq. (1) expresses the trade-off households make in their location choice, between housing space, goods consumption and potential health impacts from traffic-induced air pollution.

Households have income $Y$ available to spend on location-dependent housing rent $R(r)$, the composite good $Z(r)$ and mode-choice dependent commuting costs $T(r)$ to the CBD.

$Y \geq H(r) R(r)+Z(r)+T(r)$

The average exposure during the commuting journey $E_{C}$ for a household residing at location $r$ is a function of the local mode share and mode-specific pollutant doses

$E_{C}(r)=\left(p_{C}(r) D_{C}(r)+p_{T}(r) D_{T}(r)\right) /\left(p_{C}(r)+p_{T}(r)\right)$

where $p_{C}(r)$ and $p_{T}(r)$ are the shares of households commuting by car and by train (plus walking or biking) respectively at location $r$, with $p_{C}(r)+$ $p_{T}(r)=1$ as given by the travel mode choice model.

$D_{C}(r)$ or $D_{T}(r)$ is the dose of pollution concentration taken up depending on the transport mode. The dose along a journey to work is expressed by the pollution concentration being breathed in during the journey.

The pollutant dose [in $\mu g$ ] is a function of pollutant concentration $c$ at a location $r$, duration $d$ of exposure, and breathing rate $b$ depending on the type of activity $i$. Activities are commuting by car, by train, by bike/ walking, and being at home.

$D_{i}(r)=c(r) d_{i} b_{i}$

The pollutant dose taken up at the residential location can be expressed as

$E_{R}(r)=D_{R}(r)=c(r) d_{R} b_{R}$

where $D_{R}(r)$ is the pollutant dose at the residential location given by (4) for residential activity, that is the local pollution concentration $c$ at the residential location, breathing rate while being at home $b_{R}$ and time spent at the residential location $d_{R}$ (considering mode-choice dependent 


\section{Joint Urban-Transport Equilibrium}

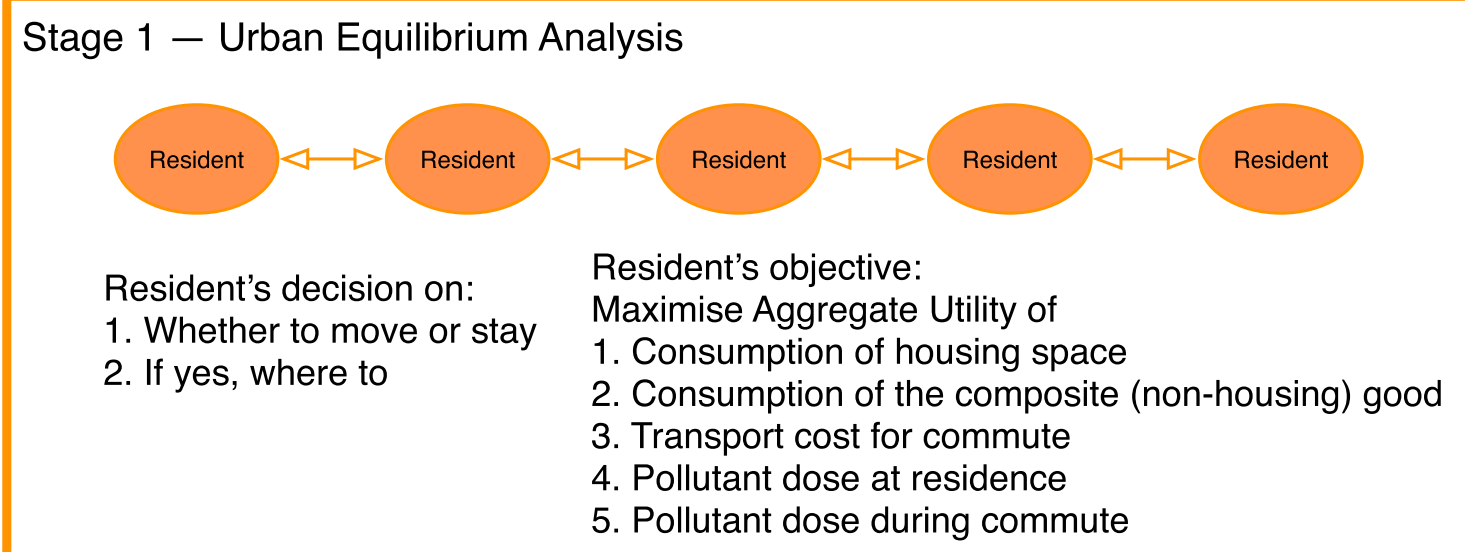

\begin{tabular}{c|ccc}
$\begin{array}{c}\text { Spatial } \\
\text { distribution } \\
\text { of }\end{array}$ & $\begin{array}{c}\text { Mode } \\
\text { choice of } \\
\text { each user } \\
\text { population }\end{array}$ & $\begin{array}{c}\text { Pollutant } \\
\text { dose at } \\
\text { at each } \\
\text { location }\end{array}$ & residence \& \\
during \\
commute
\end{tabular}

\section{Stage 2 - Transport Equilibrium Analysis}

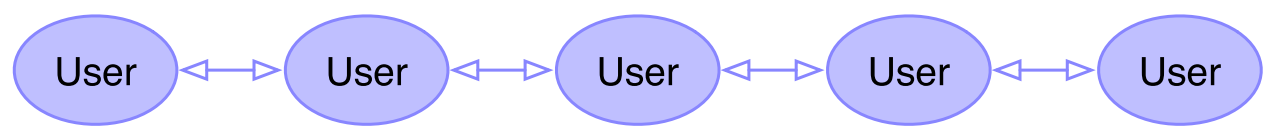

User's decision on transport mode: User's multiple objectives:

1. Car

2. Walk/cycle + rail

3. Walk/cycle only
1. Minimise travel time

2. Maximise travel time reliability

3. Minimise monetary cost

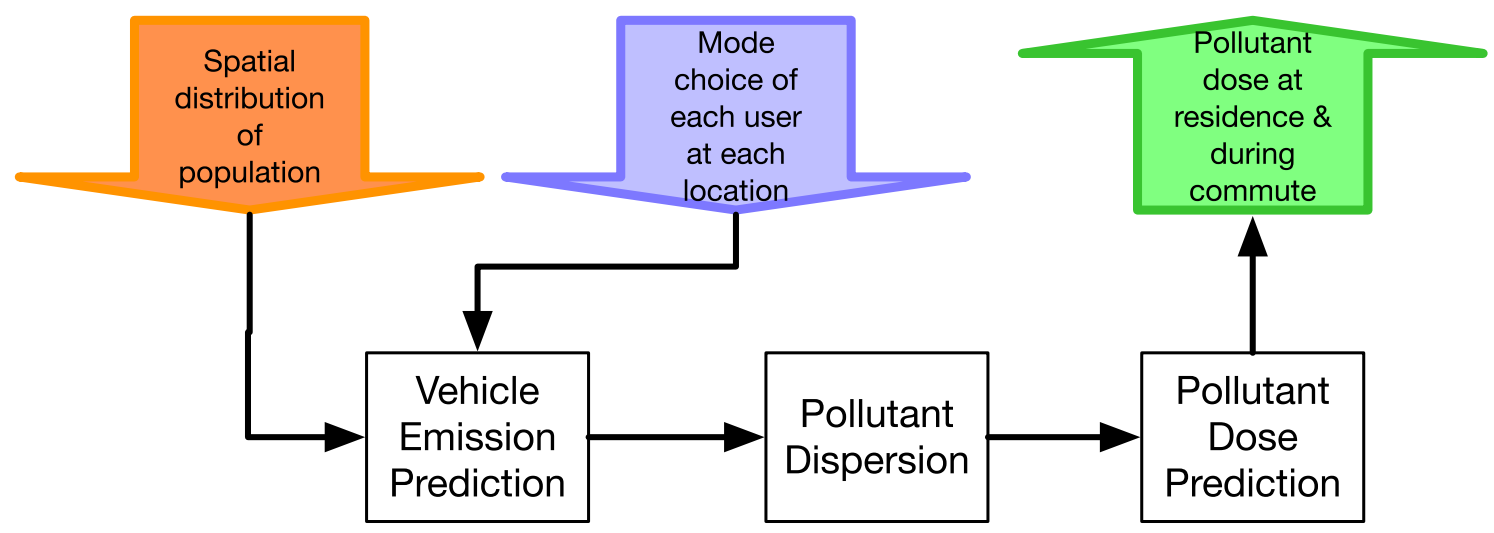

\section{Pollutant Dose Analysis}

Fig. 2. A two-stage game theoretical approach for a joint urban-transport equilibrium.

travel time).

\subsubsection{Transport mode choice model}

Transport mode choice is based on the bi-modal TUE model proposed in Wang and Connors (2018); the key concepts are briefly presented here. Travellers trade-off three objectives: (1) minimise travel time; (2) maximise travel time reliability; and (3) minimise monetary cost. For walking, cycling and train, the travel time is distance-based and has (fixed) reliability of $95 \%$. Car travel suffers from congestion, having a travel time distribution whose mean and variance increase with the volume of car traffic.

Each user has their own desired level of reliability (i.e. the probability of arriving at the destination on time), which is uniformly distributed between $50 \%$ and $95 \%$ at every location throughout the LMC. Desired arrival time reliability infers a necessary departure time, and hence the associated travel time budget (TTB) can be computed (Lo et al., 2006). Individuals trade-off TTB and monetary cost according to the travel time budget surplus (TBS) concept (Wang and Ehrgott, 2018). 


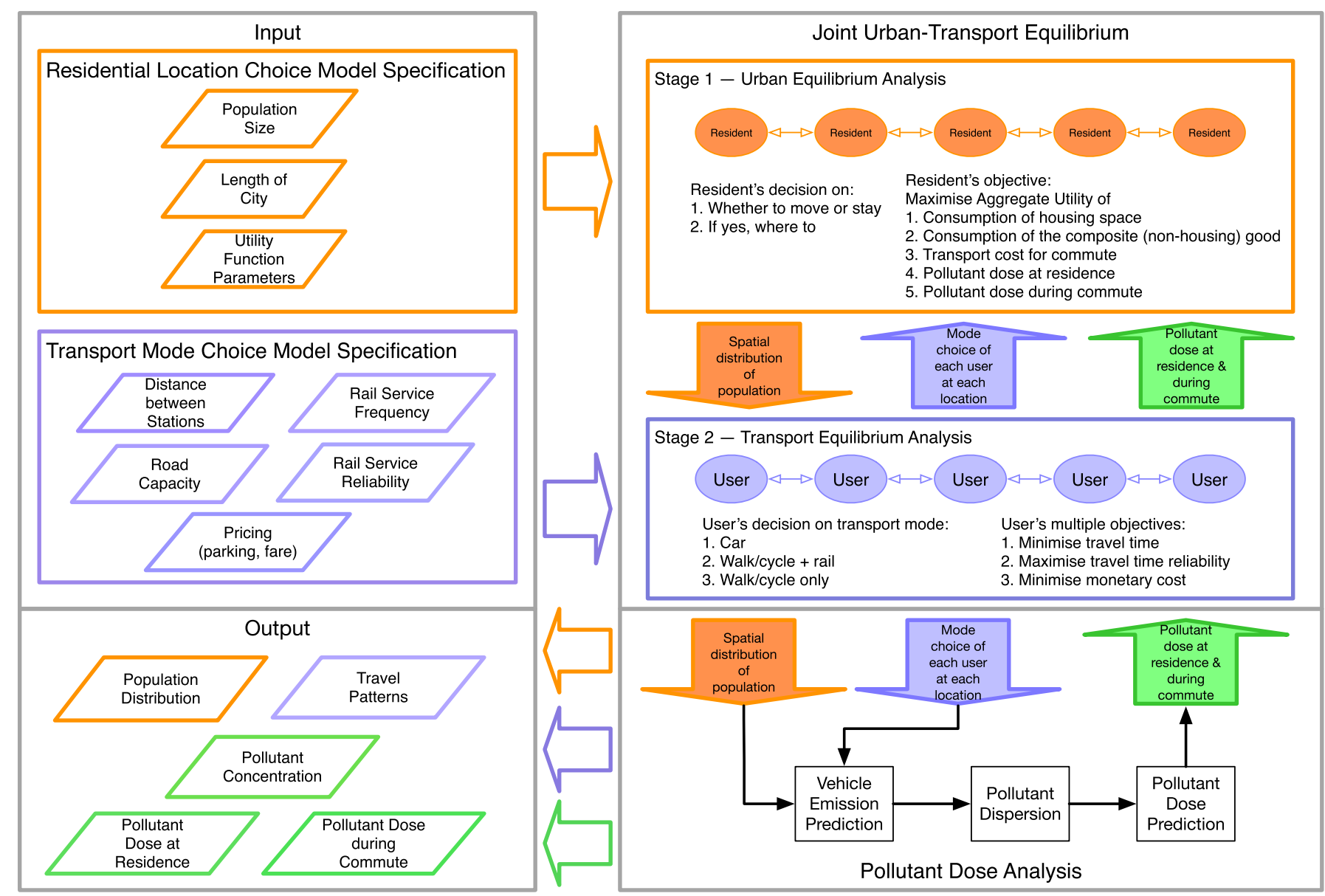

Fig. 3. Model flow of the joint urban-transport equilibrium model, including inputs and outputs of each model components and feedback links.

For any given price (monetary cost), an individual will have a maximum TTB that they would be willing to spend; this is captured by the indifference curve for this individual, along which the alternatives are equally attractive.

TBS is the maximum TTB minus the required TTB for the desired level of reliability. Individuals choose the option with the highest TBS, so that equilibrium is reached when no individual can improve their TBS by switching mode. This is called the travel time budget surplus maximisation three-objective user equilibrium (TBSmaxTUE) condition.

The equilibrium modal split is specific to each location. Fig. 4 shows rail with fixed $95 \%$ reliability and positive TBS. The necessary TTB for car depends on the individual's desired reliability, with $i \%$ giving the same TBS as rail. Individuals with desired reliability $<i$ will choose car, and the rest will choose rail.

Given the demand distribution throughout the city, TBSmaxTUE provides the transport equilibrium solution for the system, i.e. the modal split between rail and car at each location.

\subsubsection{Pollutant dose analysis}

Based on the spatial distribution of the residents and modal split at each location from transport equilibrium analysis, we can derive the link flow, average speed and travel time on all modes (including not only car and rail, but also the access modes, walking and cycling). We can then proceed to a three-stage analysis as illustrated in Fig. 2 adopted from Wang and Connors (2018):

1. Vehicle Emission Prediction - modelling emission rates for the road based on traffic flow and average vehicle speed (Rilett and Benedek, 1994).

2. Pollutant Dispersion - modelling air pollutant concentrations

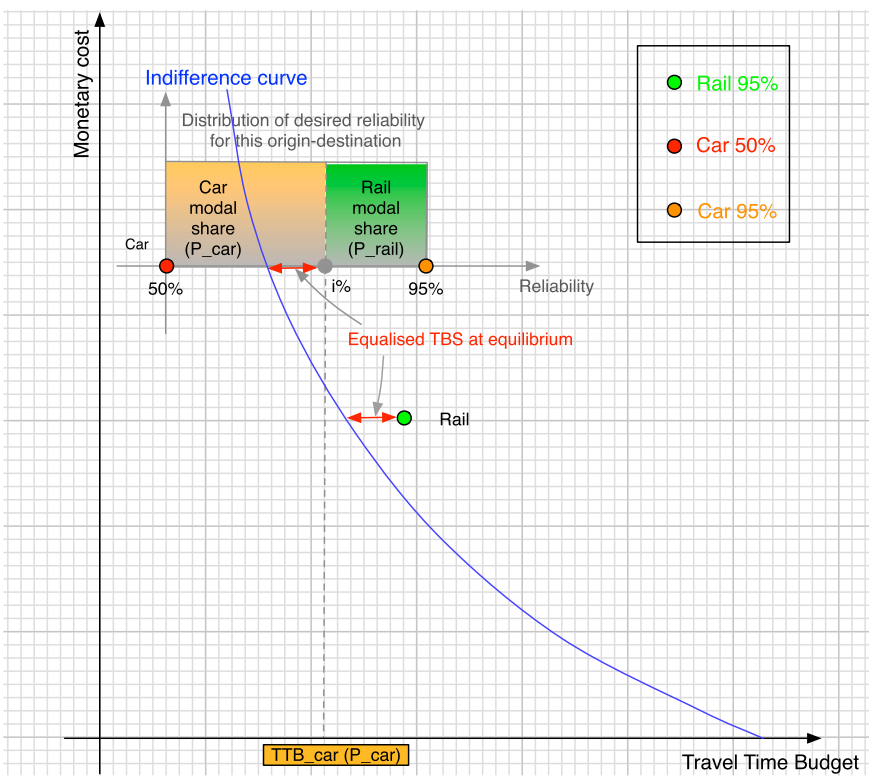

Fig. 4. Both car and rail have positive modal shares (taken from Wang and Connors (2018)).

from road emission rates and surface meteorology (Dirks et al., 2002, 2003). This determines the local pollutant concentration at each residential location. 
3. Pollutant Dose Prediction - modelling pollutant dose from air pollution concentrations and the travel time along each link on the commute including the active (walking/cycling) component, following Dirks et al. (2012) as explained in Eq. (3) and (5).

Thus, we will be able to estimate the individual pollutant dose, by aggregating the pollutant dose on different modes (including access/ active modes, i.e. walking and cycling) during the journey to work.

\subsection{Joint urban-transport equilibrium solution algorithm}

As explained and visualised in Fig. 2, there is a feedback loop between the residential location choice model, the transport mode choice model and the pollutant dose analysis. Given the transport equilibrium as explained in Section 2.2.2, the joint urban-transport equilibrium can be obtained as follows.

In urban equilibrium all households get the same utility $u$ assuming migration is free and households are identical. The boundary of the city $r_{f}$ and the total population $N$ are assumed to be fixed in the closed city. Households choose a residential location where they can maximise their utility expressed in Eq. (1), subject to the average pollutant dose during the commuting journey of all transport modes according to the local modal split, the pollutant dose at the residential location, the rent and housing profile, and the budget constraint.

We assume that the dose, physical activity and transport monetary cost for a residential location is an aggregate function of these performance parameters by mode, weighted by the current modal split. This means that an individual considers the possible performances of the two modes and would assess the aggregate performance according to the current modal split at this location. This reflects the possibility of individuals to change their mode choice on a low temporal scale, while a general mode split at a location can be observed on a larger temporal scale.

The urban equilibrium is defined by the functions $Z(r), H(r), R(r)$, pollutant dose levels $E_{R}(r)$ and $E_{C}(r)$ given by the transport model, and the land allocation condition $R(r)=\max \left\{\Psi(r), R_{A}\right\} . R_{A}$ is the constant agricultural rent beyond the city boundary $r_{f}$ and $\Psi(r)$ is the land bid rent given by

$\Psi(r)=\max \frac{Y-T(r)-Z(r)}{H(r)}$ s.t. $N=\int_{0}^{r_{f}} n(r) d r$

In the following, we drop $r$ for conciseness where it causes no confusion.

\subsubsection{Consumption}

Households' demand functions for housing $H$ and the composite good $Z$ at each residential location are derived from the maximisation problem (6)

$Z=(1-\alpha)(Y-T)$

$H=\alpha u^{* 1 / \alpha} E_{R}^{\beta / \alpha} E_{C}^{\gamma / \alpha}(Y-T)^{1-1 / \alpha}$

where $u^{*}=u\left(Z, H, E_{R}, E_{C}\right)$ is the endogenous utility reached by all households at all locations in equilibrium. Eq. (8) shows that households compensate higher pollutant doses and higher transport costs with increased housing consumption or lower rent payments. A stronger aversion to exposure, ceteris paribus, also increases housing consumption, highlighting the trade-off households make when deciding where to live.

\subsubsection{Population density}

Since we assume that all residential space at a location is occupied and normalised to 1 , we have $n=1 / H$, and thus the population density $n$ can be expressed as

$n=\alpha^{-1} u^{*-1 / \alpha} E_{R}^{-\beta / \alpha} E_{C}^{-\gamma / \alpha}(Y-T)^{1 / \alpha-1}$
Population density is thus a function of residential preferences $(\alpha, \beta$, $\gamma$ ), pollutant doses $\left(E_{R}, E_{C}\right)$, income $(Y)$, transport costs $(T)$, and the endogenous utility level $\left(u^{*}\right)$. Given the closed city framework, the population constraint $N=\int_{0}^{r} n(r) d r$ must hold.

\subsubsection{Land rent}

Under Cobb-Douglas preferences housing expenses are equal to the share of income spent on housing minus commuting costs: $R H=\alpha(Y-$ $T$ ). With Eq. (8) we can derive the land rent as a function of income, transport costs, pollutant doses at the residential location and during the commuting journey, residential preferences, and the endogenous utility level:

$R=u^{*-1 / \alpha}(Y-T)^{1 / \alpha} E_{R}^{-\beta / \alpha} E_{C}^{-\gamma / \alpha}$

Land rent at the city boundary $R\left(r_{f}\right)$ is then

$R\left(r_{f}\right)=R_{A}=u^{*-1 / \alpha}\left(Y-T\left(r_{f}\right)\right)^{1 / \alpha} E_{R}\left(r_{f}\right)^{-\beta / \alpha} E_{C}\left(r_{f}\right)^{-\gamma / \alpha}$

\subsubsection{Equilibrium utility}

Since the fringe distance $r_{f}$ is assumed to be fixed and the rent at the urban boundary equals the agricultural rent such that $R\left(r_{f}\right)=R_{A}$, we can use Eq. (11) to derive the endogenous utility level $u^{*}$ which all households have to obtain no matter their location or mode choice

$u^{*}=\left(Y-T\left(r_{f}\right)\right) R_{A}^{-\alpha} E_{R}\left(r_{f}\right)^{-\beta} E_{C}\left(r_{f}\right)^{-\gamma}$

This property shows as expected that utility is positively related to income, but negatively to transport costs, agricultural rent, and pollutant doses at home and during the commute. With the pollution concentration from traffic at the city boundary being the lowest within the city (only background concentration or non-traffic related pollution), $E_{R}\left(r_{f}\right)$ can be assumed constant. Thus, we can show that trafficinduced residential exposure does not change the population at the city boundary. $T\left(r_{f}\right)$ and $E_{C}\left(r_{f}\right)$, however, depend on the distribution of households and modal splits in the city. Thus, these two model components alter the population density at the city boundary.

\section{Numerical analysis}

\subsection{Process, scenarios and parameters}

We analyse the described continuous model numerically, by splitting the interval $r \in[0, L]$ representing the city space into $X$ discrete elements so that $d r=L / X$.

The numerical analysis is initialised with a uniform population distribution of $n(r)=N / X$. For each location, the transport mode choice is calculated as explained in Section 2.2.2, returning the modal split by location. Based on the modal split, vehicle emissions are calculated and their dispersion obtained as pollutant concentrations per location. Depending on the average modal split per location, the average dose per commute to the CBD is calculated for each location. Also, doses at residential locations are estimated. Given this information about the potential dose per residential location - during the commute and/or at the residency - bid rents and utilities per location are obtained as explained in Section 2.3. A household residing at a location with the lowest utility in the current iteration moves to a location with the highest utility. In case several locations meet these criteria, households and locations are drawn randomly from this subset. Based on the updated population distribution, mode choices are updated and the entire process is repeated until convergence, i.e. differences in utilities across locations are smaller than a given threshold value. For further details on the mathematical formulation of the mode choice model, the reader is referred to Wang and Connors (2018).

The model allows to consider any primary traffic-induced pollutant. We model carbon monoxide (CO), a major non-reactive primary pollutant that results from incomplete oxidation of carbon in 
combustion and impacts human health.

We numerically analyse four scenarios with fixed population $N$ : (i) the benchmark case, where residents do not express any concern related to air pollution (neither exposure at the residential location nor during the commute); (ii) residents are concerned about residential exposure; (iii) residents consider both residential and commuting exposure in their decision-making process; and (iv) travellers only consider their exposure during the commute to work. The numerical results of these scenarios are depicted in Figs. 5 to 11.

Table 1 lists the model parameters and Table 2 shows the parameter values that change across scenarios. Default model parameters were chosen based on those used for the model with car travel only in Schindler et al. (2017) and the transport choice model in Wang and Connors (2018), which themselves selected model parameters based on literature where applicable and to suit the chosen set of comparative scenarios.

\subsection{Results}

In the following, we present the results of our numerical analysis, including aggregate results across scenarios (Table 3 ) and spatial patterns of the scenarios. Note that these results are valid for the specified parameter space, in particular where households' preferences for housing space are always higher than their aversion to localised pollution. ${ }^{1}$

\subsubsection{Population distribution}

Fig. 5 shows the population distribution as a function of distance to the CBD (located at $r=0$ ) for the different scenarios. Without any pollution-related concerns (benchmark, red dashed line), population density is highest in locations close to the CBD and the train station located at $r=0$, followed by locations close to other train stations located at $r=5 ; 10 ; 20$ ). In general, population density decreases with distance to the centre. Locations close to train stations are attractive locations due to travel time, reliability, and travel costs (see also Wang and Connors (2018)); thus, we find population clusters around these transport stations.

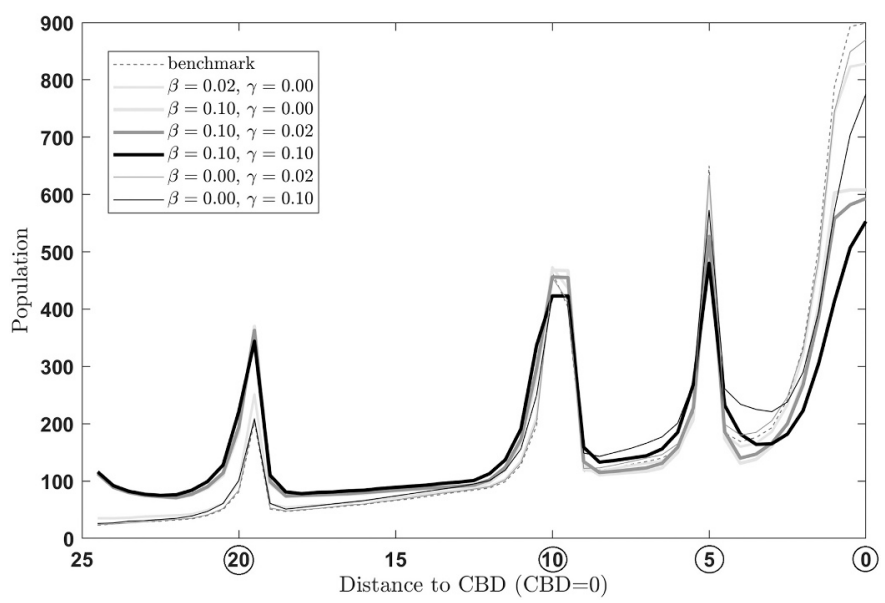

Fig. 5. Population distribution as a function of distance to the CBD depending on households' residential preferences ( $\beta$ and $\gamma$ ); train stations are located at distances 0;5;10 and 20 (circled).

\footnotetext{
1 This is a reasonable assumption; Schindler et al. (2017) have discussed analytically boundary conditions for their residential location choice model to yield qualitatively different results. Due to analytical intractability in our integrated location and mode choice model this is beyond the scope of this paper.
}

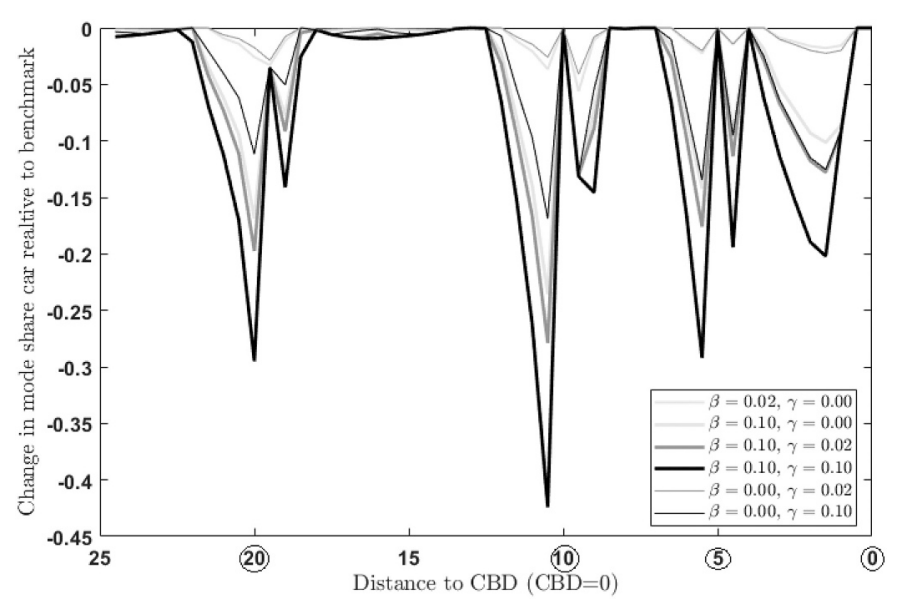

Fig. 6. Car mode share as a function of distance to the CBD depending on households' residential preferences $(\beta$ and $\gamma$ ) - changes for all scenarios relative to the benchmark scenario. Train stations are located at distances $0 ; 5 ; 10$ and 20 (circled).

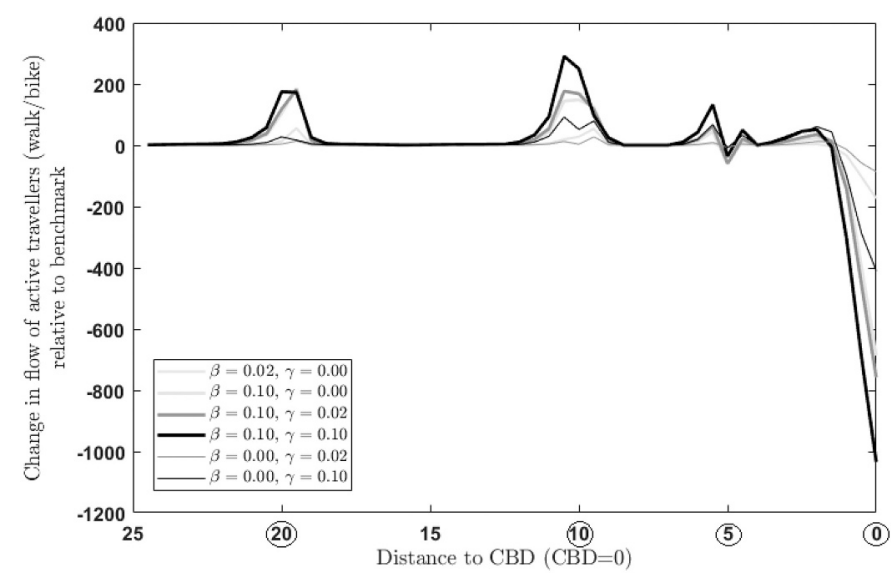

Fig. 7. The flow of biking and walking (active transport modes) as a function of distance to the CBD depending on households' residential preferences ( $\beta$ and $\gamma$ ) - changes for all scenarios relative to the benchmark scenario. Train stations are located at distances $0 ; 5 ; 10$ and 20 (circled).

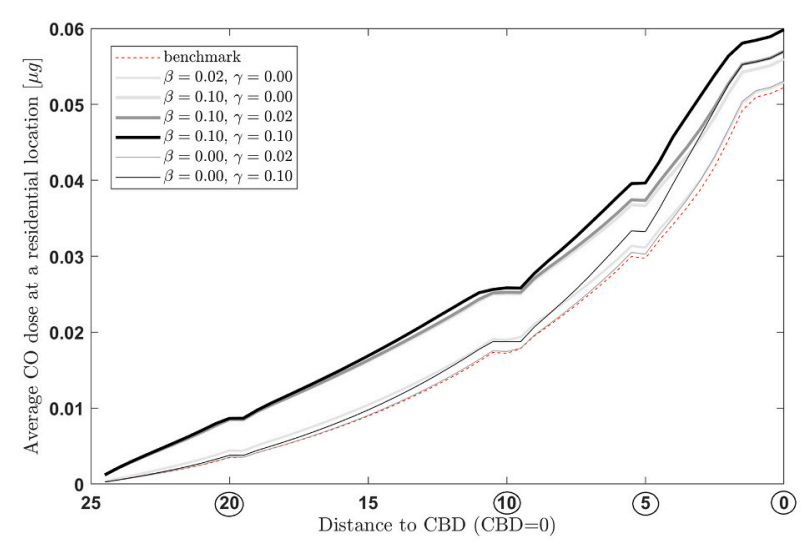

Fig. 8. CO doses at residential locations as a function of distance to the CBD depending on households' residential preferences $(\beta$ and $\gamma)$; train stations are located at distances $0 ; 5 ; 10$ and 20 (circled). 


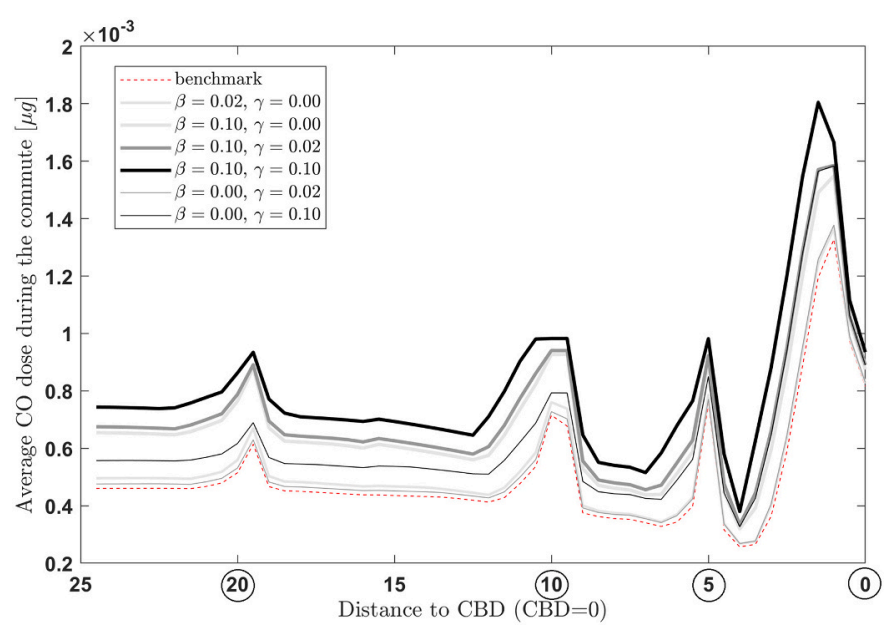

Fig. 9. CO doses during the commute as a function of distance to the CBD depending on households' residential preferences $(\beta$ and $\gamma$ ). Train stations are located at distances $0 ; 5 ; 10$ and 20 (circled).

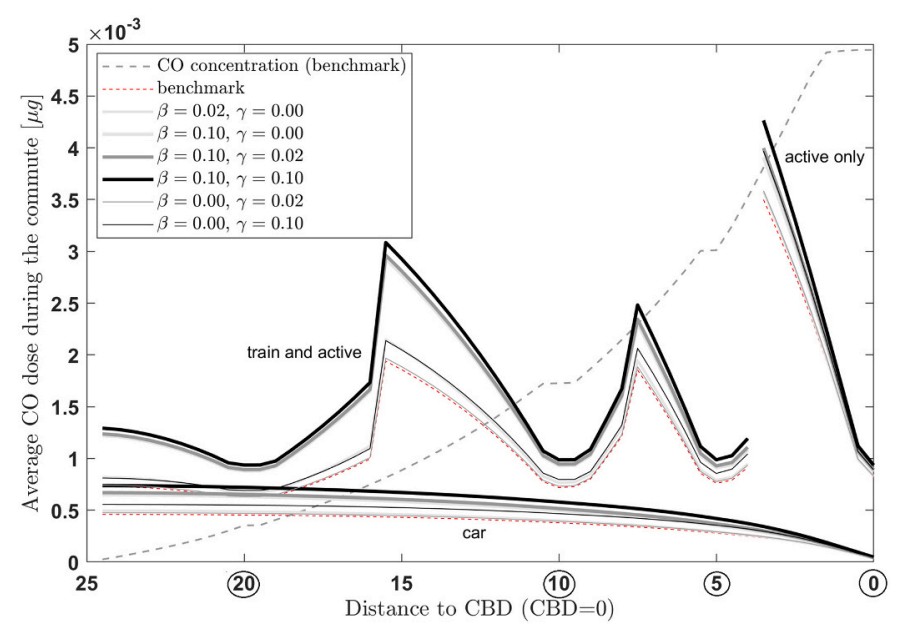

Fig. 10. CO doses during the commute, experienced by households living at locations $r \mathrm{~km}$ away from the CBD depending on their mode of transport and their residential preferences $\beta$ and $\gamma$; the grey line depicts CO concentrations for the benchmark scenario $(\beta=\gamma=0)$ as a function of distance to the CBD. Train stations are located at distances $0 ; 5 ; 10$ and 20 (circled).

As households are concerned about being exposed to traffic-induced air pollution at the residential location $(\beta>0$, increased line width), central locations become less attractive residential locations while locations near the city boundary attract more households. Households compensate the higher $\mathrm{CO}$ doses in central locations by demanding more housing space in order to receive the same utility as elsewhere in the city; thus, compared to the benchmark scenario we find lower population densities near the centre since $\mathrm{CO}$ doses are lower near the city boundary than near the centre, and households therefore accept higher population densities (i.e. each household consumes less housing space) in suburban locations than in the benchmark case. Thus, local pollution externalities increase population densities in suburban locations, and reduce densities close to the $\mathrm{CBD}$.

Factoring a concern about exposure during the commuting trip $(\gamma>$ 0 , darker lines) into residential choices results in more households living in locations between the CBD and the train station at $r=5$. In the most central locations, however, population densities are still lower than in the benchmark scenario since households compensate the commute exposure with increased housing space. Therefore, we observe that households with both types of air pollution related concern choose
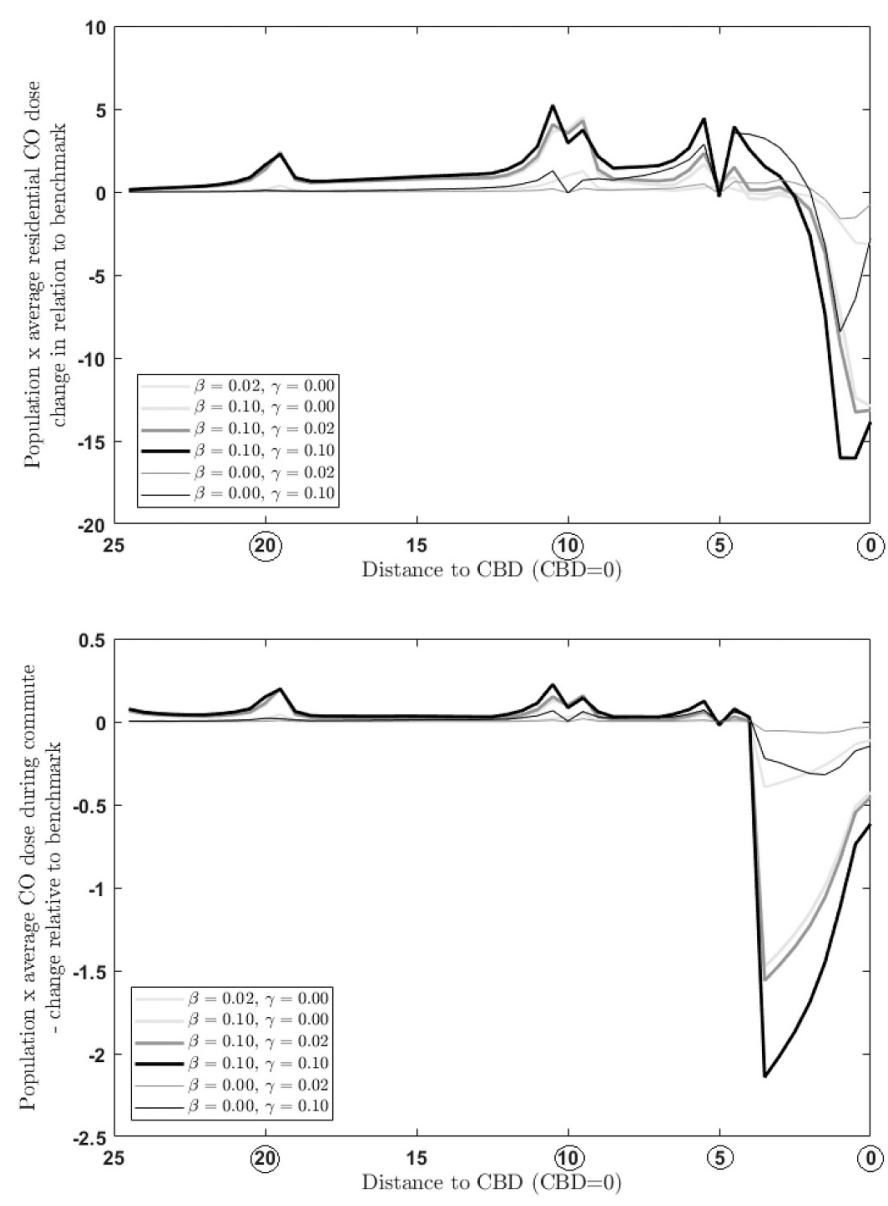

Fig. 11. Average CO dose experienced by all residents living at a location $r \mathrm{~km}$ away from the CBD depending on households' residential preferences ( $\beta$ and $\gamma$ ) relative to the benchmark scenario; a) dose at a residential location $r \mathrm{~km}$ from the CBD, b) average dose during the commute of all households living at location $r$. Train stations are located at distances 0;5;10 and 20 (circled).

Table 1

Model parameters.

\begin{tabular}{lll}
\hline Parameter & Description & Default value \\
\hline$N$ & Number of households & 9000 \\
$s_{i}$ & Locations of railway stations & $0 ; 5 ; 10 ; 20$ \\
$r_{f}$ & Location of the city boundary; & 1 \\
$L$ & city length (km) & 25 \\
$X$ & Number of discrete elements between [0,L] & 50 \\
$R_{A}$ & Agricultural rent (£/month) & 1 \\
$Y$ & Household income (£/month) & 2000 \\
$D_{W}, D_{B}$ & Maximum walking, cycling distance (km) & $0.5 ; 10$ \\
$f_{C}, f_{T}, f_{W}, f_{B}$ & Speed (km/min) by car (free flow), train, walk, & $0.75 ; 1.2 ; 15 ; 6$ \\
& bike & \\
$W_{T}$ & Waiting time for train (min) & 15 \\
$E_{T}$ & Egress time (min) from station & 5 \\
$m_{T}, m_{C}$ & Cost (£/km by train (ticket), by car (fuel) & $0.15 ; 0.12$ \\
$\tau$ & Willing to pay (£/km) to get free flow speed & 1 \\
$c_{C}$ & Road capacity (veh/h) & \\
$T_{C} P, T_{B} P$ & Parking time (min) for car, bicycle & $3 ; 4.5$ \\
$P_{C}$ & Cost to park car(£) & 3 \\
$c, k$ & Burr Distribution shape parameters & $10 ; 0.7$ \\
$b_{R}, b_{W}, b_{B}$ & Breathing rate (cu.m/min) resting, walking, & $0.012 ; 0.024 ; 0.036$ \\
& cycling & \\
\hline
\end{tabular}

larger housing spaces, albeit in different locations away from the centre: residential concerns disperse population notably to suburban locations with public transport access; while commuting concerns concentrate population notably close to, but not in, the CBD. 
Table 2

Households' residential preferences per scenario;' $\mathrm{B}^{\prime}$ : benchmark, no exposure concerns, 'R': only concerns about exposure at the residential location,'RC': concerns about both residential and commuting exposure,' $\mathrm{C}$ ': only concerns about commuting exposure.

\begin{tabular}{llllll}
\hline & Description & B & R & RC & C \\
\hline$\alpha$ & $\begin{array}{l}\text { Preference for housing } \\
\text { space }\end{array}$ & $\begin{array}{l}0.2 \\
\text { [B] }\end{array}$ & 0.2 & 0.2 & 0.2 \\
$\beta$ & $\begin{array}{l}\text { Aversion to exposure } \\
\text { at the residential } \\
\text { location }\end{array}$ & 0 & $\begin{array}{l}0.02 ; 0.10 \\
\text { [R1] }\end{array}$ & $0.10[\mathbf{R C 1}]$ & $0[$ [C1] \\
$\gamma$ & $\begin{array}{l}\text { Aversion to exposure } \\
\text { during the commute }\end{array}$ & 0 & $0[\mathbf{R 2}]$ & $\begin{array}{l}0.02 ; 0.10 \\
{[\mathbf{R C 2}]}\end{array}$ & $\begin{array}{l}0.02 ; 0.10 \\
{[\mathbf{C 2}]}\end{array}$ \\
\hline
\end{tabular}

between car and active commuters needs to be considered in policy design to avoid unintentional consequences, as further discussed in Section 4.

\subsubsection{CO doses}

Residents are exposed to different $\mathrm{CO}$ doses depending on the variations in $\mathrm{CO}$ concentrations across the city, where they live, and the different breathing rates and journey times dependent on the different transport modes.

Interestingly, on aggregate, the $\mathrm{CO}$ concentration increases relative to the benchmark in all scenarios, with a maximum for RC2 (Table 3). A stronger aversion lets households compensate $\mathrm{CO}$ doses with the consumption of more housing space and, therefore, shifts more households

Table 3

Aggregate results for the seven scenarios; the scenario with the maximum value per row is marked in bold.

\begin{tabular}{|c|c|c|c|c|c|c|c|}
\hline & B & R1 & R2 & RC1 & RC2 & C1 & C2 \\
\hline \multicolumn{8}{|l|}{ Travel patterns } \\
\hline Car commuters & 4182.555 & 4214.123 & 4351.749 & 4393.877 & 4507.987 & 4223.091 & 4392.645 \\
\hline Train commuters & 4817.445 & 4785.877 & 4648.251 & 4606.123 & 4492.013 & 4776.909 & 4607.355 \\
\hline Commuters $\geq 10$ min active & 471.953 & 472.047 & 501.549 & 517.637 & 524.562 & 484.795 & 531.516 \\
\hline Commuters active travel only & 2950.733 & 2777.199 & 2264.758 & 2192.501 & 1916.217 & 2864.233 & 2540.266 \\
\hline Average speed car $[\mathrm{km} / \mathrm{min}]$ & 1.228 & 1.219 & 1.174 & 1.168 & 1.149 & 1.223 & 1.199 \\
\hline Ratio average time train/car & 2.253 & 2.231 & 2.129 & 2.109 & 2.049 & 2.236 & 2.154 \\
\hline \multicolumn{8}{|l|}{ CO doses $[\mu g]$} \\
\hline CO concentration & 18.067 & 19.303 & 24.255 & 24.643 & 25.926 & 18.397 & 20.141 \\
\hline Max. CO dose (residential) & 0.052 & 0.053 & 0.056 & 0.057 & 0.060 & 0.053 & 0.057 \\
\hline Max. CO dose (commute) & 0.001 & 0.001 & 0.002 & 0.002 & 0.002 & 0.001 & 0.002 \\
\hline Max. CO concentration & 0.005 & 0.005 & 0.005 & 0.005 & 0.005 & 0.005 & 0.005 \\
\hline CO dose active travel only & 50.184 & 48.072 & 42.218 & 41.713 & 38.585 & 49.746 & 48.186 \\
\hline \multicolumn{8}{|l|}{ Population exposure $[\mu g]$} \\
\hline residential & 0.890 & 0.950 & 1.189 & 1.208 & 1.269 & 0.906 & 0.991 \\
\hline commute & 0.025 & 0.027 & 0.034 & 0.036 & 0.040 & 0.026 & 0.032 \\
\hline Utility & 2.226 & 2.403 & 3.219 & 3.717 & 6.546 & 2.586 & 4.634 \\
\hline
\end{tabular}

\subsubsection{Travel patterns}

The change in population distribution due to air pollution related concerns (all scenarios but the benchmark) results in more households travelling by car than train and/or active travel mode (Table 3). In particular fewer households bike or walk directly to work and more households commute longer distances. Yet more households travel actively (i.e. walk/bike) for more than $10 \mathrm{~min}$ (see Figs. 7;A.6). The average car travel speed decreases and the ratio between travel time by train compared to car increases relative to the benchmark scenario.

In terms of transport mode choice, we see that all households living close to train stations $(r=0 ; 5 ; 10 ; 20)$ choose to commute by train (and walking/biking), while households near the city boundary and further away from train stations commute mostly by car (Fig. 6). Most households near the CBD walk or bike directly to work. This pattern is quite constant across scenarios, with most changes observed around train stations and the CBD as the highway becomes more congested. Since fewer households live in central locations relative to the benchmark scenario in case of high $\beta$, we observe more car travellers commuting from more distant locations relative to the benchmark. An increase in $\gamma$, in contrast, increases the amount of car travellers mainly in locations some distance away from the CBD $(r=4 ; 6 ; 9)$.

Fig. 7 shows the flow of walkers and bikers as a function of distance to the CBD. Active modes of transport are chosen by households who live close enough to the CBD to directly walk or bike to work, and by households to get to the nearest train station. Thus, we see a cluster of active commuters around train stations and the CBD. It is interesting to note that across scenarios, we observe a drop in active modes (hence an increase in car use) in central locations as households are more concerned about exposure to air pollution, especially about exposure during the commute. In contrast, such concerns result in increased flows of active commuters around suburban train stations. This spatial tension further away from the CBD (see Fig. 5 and the trade-off in the utility function ${ }^{2}$ in Eq. (1)), resulting in longer commuting distances and hence increased emissions. The more congested highway also amplifies CO concentrations in the city. Since fewer households are biking/walking directly to the CBD (where CO concentrations are highest), total CO dose for this group is lower.

Fig. 8 shows the average dose households are exposed to at residential locations, as a function of distance to the CBD. Doses decrease with distance to the CBD, with steeper reductions in locations which are far away from train stations. This is due to varying commuting times across locations, depending on commuting mode and distance to the CBD. Since households move further away from the centre as they are more concerned about being exposed at their residential locations, travel distances are increased and, in turn, pollution concentrations and CO doses are increased in locations around the CBD.

This generally follows the pattern of $\mathrm{CO}$ concentrations, which decrease with distance to the centre. All households are commuting to the CBD, thus emission concentrations are highest close to the centre. However, since households who live close to the centre walk or bike to work, CO concentrations almost stagnate in central locations. Similarly, many households living close to train stations bike or walk to the stations, and, therefore, do not contribute to emissions. Hence, there is few variation around the locations of train stations. When households factor health concerns due to traffic-induced air pollution into their location choice, we see slightly increased CO concentrations in particular in central locations due to increased travel distances as more households live in suburban locations.

\footnotetext{
${ }^{2}$ Note that the preference for housing space consumption is always higher than the aversion to pollution in this numerical example (Table 2).
} 
The total (aggregate) CO concentration varies across scenarios. The benchmark scenario yields the lowest total CO concentration $(18 \mu g)$, while the scenario with the strongest concern about both exposure during the commute and at the residential location yields the highest total concentration in the city $(25.9 \mu \mathrm{g})$.

Looking at the spatial pattern of CO doses during the commuting trip (Fig. 9), we see that maximum doses are experienced by households living some distance away from the CBD, and not by households living closest to the CBD. This is because central households directly walk or bike into the CBD and, therefore, spend less time commuting; at the same time, however, they are exposed to highest emission concentrations while having increased breathing rates due to their active mode of transport. A short commute offsets these high concentrations, a longer commute, however, leads to increased doses; hence the peak at distance $r=2$.

Lowest doses are found at locations somewhat close to the CBD, but where households commute by car. These households have a relatively short commute and a low breathing rate, and therefore experience only low doses. Fig. 10 illustrates well the trade-off between active commuting mode (hence higher breathing rate), commuting time, and emission concentrations as a function of distance to the CBD. These results highlight how CO doses vary per residential location and per transport mode, and across scenarios.

The benchmark scenario yields the lowest CO doses at a residential location, with the most pronounced differences found in central locations (Figs. 9 and 10) and among active commuters.

\subsubsection{Population exposure}

Looking at population exposure gives another interesting perspective. Residential population exposure is obtained by multiplying $\mathrm{CO}$ doses at a residential location by the number of households living there (Fig. 11a). Commuting population exposure is obtained similarly by multiplying the average CO dose during the commuting journeys of households living at a location by the number of households (Fig. 11b).

On aggregate, total population exposure (both residential and commute) is highest in RC2, followed by RC1, and lowest in the benchmark scenario.

We see that households' health concern in location choice has the most prominent effect in central locations (Fig. 11). The benchmark scenario (no concern) results in highest population exposure in central locations due to highest population and CO concentrations there. Residential exposure concern leads households to shift towards locations further away from the CBD, and therefore to avoid locations with highest emission concentrations. In case of concerns about exposure during the commute, more people choose locations somewhat close to the $\mathrm{CBD}$, and hence accept higher doses at residential locations while reducing commuting time and, therefore, the time being exposed. A concern about exposure at home leads more households to choose suburban locations, resulting in increased travel distances by car, hence higher emissions and hence higher $\mathrm{CO}$ doses in central locations. Fig. 11 illustrates the tension between exposure and emissions, as increased total $\mathrm{CO}$ concentrations can result in reduced population exposure in some locations due to households avoiding to live in locations with maximum concentrations.

\section{Discussion}

\subsection{Contributions of an integrated transport and residential location choice model and a call for integrated policy responses}

Developing an integrated transport and residential location choice model provides a more realistic intra-urban density pattern than a model which assumes all households commute by car as for instance proposed by (Schindler et al., 2017; Schindler and Caruso, 2021). We still observe a clear distance effect in that densities generally drop with distance to the centre (in line with urban economic theory). In addition, population clusters emerge around train stations and near the city centre. In comparison to a uniform population distribution (e.g. Wang and Connors, 2018), such an integrated model can show that the pollutant dose due to the commuting journey can actually be lowest for households that live close to the CBD and choose to make the short commuting trip by car.

\subsection{Active transport helps to reduce emissions city-wide at the cost of individuals' health in central locations}

Households which live close enough to the CBD to walk or bike are actually prone to higher doses due to higher breathing rates in active modes of transport while being exposed to the highest pollution concentrations in the city. Thus, although encouraging active transport modes within the city has great potential to reduce emission concentrations in particular in central city areas, and thus benefits the wider city population, these households are actually the subpopulation which experiences highest pollutant doses. Given that population densities are highest in central locations, this is of great concern and our work shows that if residents are aware of this tension, central locations will be less populated.

Literature discusses how different commuting modes contribute to and expose households to different pollution concentrations (e.g. Briggs et al., 2008). Although in this paper we do not account for differences in pollutant doses inside or outside vehicles, the model considers the differing breathing rates depending on the commuting mode. More active modes of transport (biking, walking) increase doses due to higher breathing rates (e.g. Wang et al., 2018). In central locations where pollution concentrations are high, this results in elevated doses for active travellers. In areas with low pollution concentrations, however, such as around train stations in suburban locations, an active mode of transport contributes to lower levels of population exposure. As visible in Fig. 11, there is a steep change in population exposure at the location $3 \mathrm{~km}$ from the CBD. Encouraging active modes of transport in suburban locations (more than central locations) can promote population health outcomes.

Households choosing to live near the city boundary in contrast, experience relatively low doses despite their longer commute. This subpopulation is responsible for highest contributions to emission concentrations as they pass all other locations on their commute to work, exclusively travel by car, and cover the longest distance. Although they experience elevated pollution concentrations themselves while working in the CBD during the day, and therefore, might consider it in their location choice, fringe locations are still the most attractive locations for them. Discouraging car travel from the city edge would be beneficial for all urban dwellers. This could be incentivised by offering public transport at the city boundary (i.e. a train station in this model). In reality, however, a train station is unlikely to mark a city boundary; instead, it will encourage further residential development beyond the train station, with many households deciding to travel all the way to the CBD by car.

\subsection{The spatiality of air pollution concern is important}

Further, we find that a concern of exposure to air pollution at the residential location tends to increase population dispersion to suburban locations, especially with access to public transport; whereas concern of exposure during the commute tends to concentrate populations closer to the CBD. The tension between those spatially differentiated concerns impacts residents' decisions, and therefore urban form and transport mode share.

Despite the mentioned differences resulting from the place of exposure concern (i.e. at home versus during the commute), we also find synergies. A trend is visible towards lower population densities in central locations but higher densities in locations in fair proximity to the CBD and public transport, independent of the place of origin of health concerns. Thus, urban policies can be designed with mutual benefits. 


\subsection{Policy interventions need to consider spatially varying impact of behaviour changes}

With increased information available to city dwellers on (real time) emission concentrations, often differentiating between areas across the city, it is important for urban planners and other decision makers to consider the effect of such information availability on people's decisions. As visible from our results, increased awareness about spatially varying pollution concentrations can actually increase inequality among subpopulations within an urban area. Although in our model all households express the same degree of concern about traffic-induced air pollution, the households which move to suburban locations are less prone to negative health outcomes than inner city dwellers. Yet, suburban households are for a large part responsible for increased pollution concentrations. This knowledge can be used by decision makers to design measures which lead households to internalise such spatial heterogeneity.

\subsection{Decision-makers: beware of unintended consequences}

Finally, our results highlight the need for decision-makers to consider unintended consequences of potential remedies: First, increased concern to exposure during the commute ironically tends to increase car use since exposure to pollution is lowest for car travellers even though they contribute most to emissions. Second, our analysis shows that air pollution-aware residents (both at the residential location and during the commute) who attempt to best manage their residential location and transport mode choices as individuals might actually deteriorate air quality at the city level. Hence, decision makers are advised to pay close attention to how to communicate with residents when aiming to raise their awareness regarding air pollution concerns.

\section{Conclusion}

This paper has presented an integrated residential location and transport mode choice model in a city with traffic-induced air pollution. We explored how behavioural changes might impact population exposure to air pollution. With increasing availability of (real time) information about air pollution concentrations and often also their spatial variability within urban areas, it becomes important for urban and transport planners and decision makers to consider the effect of such information on household behaviour. Adaptive policy design depending on the level of concern about health outcomes due to traffic-induced air pollution and underlying spatial heterogeneity of pollution sources and population exposure is key to respond to this contemporary urban issue.

With the spatially explicit and integrated urban model, we show that integrated urban and transport policies are needed to mitigate exposure to traffic-induced air pollution. Such policies need to consider residents' choices towards less populated central areas but increasingly attractive fringe areas.

We also show that policy responses might need to target different locations of a city or a combination of locations depending on whether residents are concerned about exposure at home and/or during the commute. Availability of such spatially relevant information would be key for designing appropriate policy responses for a given local context.

Our analysis further reveals the tension between impacts of behaviour changes on exposure versus emissions (pollution concentration), individual versus city outcomes, and exposure at home versus during the commute. While a household who is concerned about exposure during the commute, for instance, decides to commute by car to reduce their own commuting exposure, this might increase the total pollution concentration in the city, and thus downgrade the situation for the city as a whole, and potentially even that household at their residential location. Policy responses therefore require careful understanding of these tensions to address this trade-off, which likely varies across cities and local contexts. Low emission zones or electric vehicles might possibly help to turn this vicious cycle into a virtuous one, with less pollution making active travel more attractive.

This modelling framework offers the potential to further explore effects of transport and land use policy on residential and transport mode choice in a city with traffic-induced air pollution. It also sets the foundation for studying alternative modes of transport, such as e-bikes, and their effects on both urban structure and transport mode choice. Recent studies (e.g. Klingen and Ommeren, 2020) provide indications that increased ambient ozone levels (to which $\mathrm{CO}$ and $\mathrm{NO}_{x}$ are precursors) reduce biking speeds. This would be an interesting extension to the presented model. Further, it would be interesting to alter the city layout (e.g. train stations, city length) and explore how this might impact household behaviour and spatial patterns of exposure. An implementation of the model in a 2D modelling environment would allow for further discussion on the effect of local (neighbourhood) characteristics of urban form beyond distance effects.

\section{Author statement}

Mirjam Schindler: Conceptualization; Formal analysis; Investigation; Methodology; Project administration; Visualization; Writing.

Judith Y.T.Wang: Conceptualization; Formal analysis; Investigation; Methodology; Visualization; Writing.

Richard D. Connors: Conceptualization; Formal analysis; Investigation; Methodology; Visualization; Writing.

\section{Appendix A. Appendix}




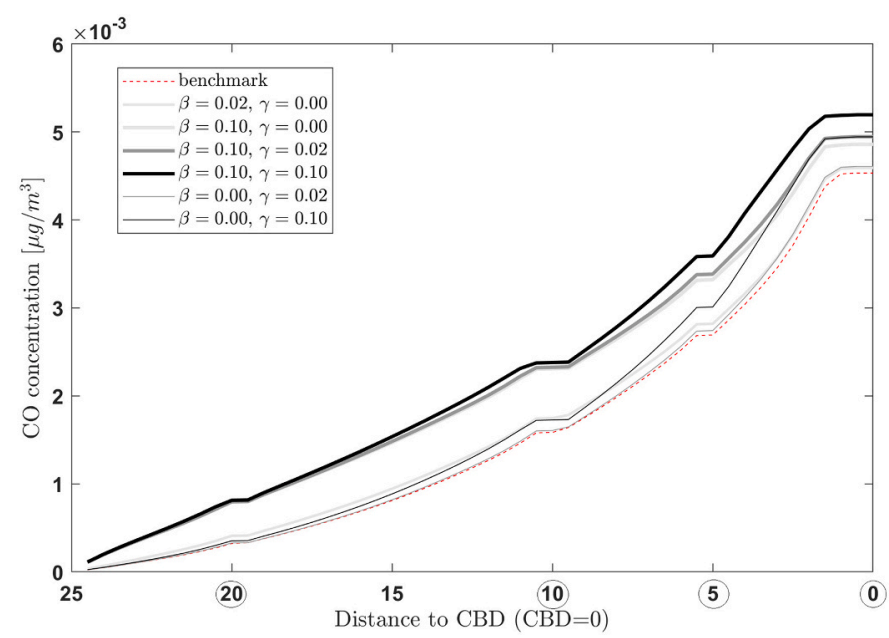

Fig. A.1. Emission concentration of $\mathrm{CO}$ as a function of distance to the CBD; train stations are located at distances $0 ; 5 ; 10$ and 20 (circled).
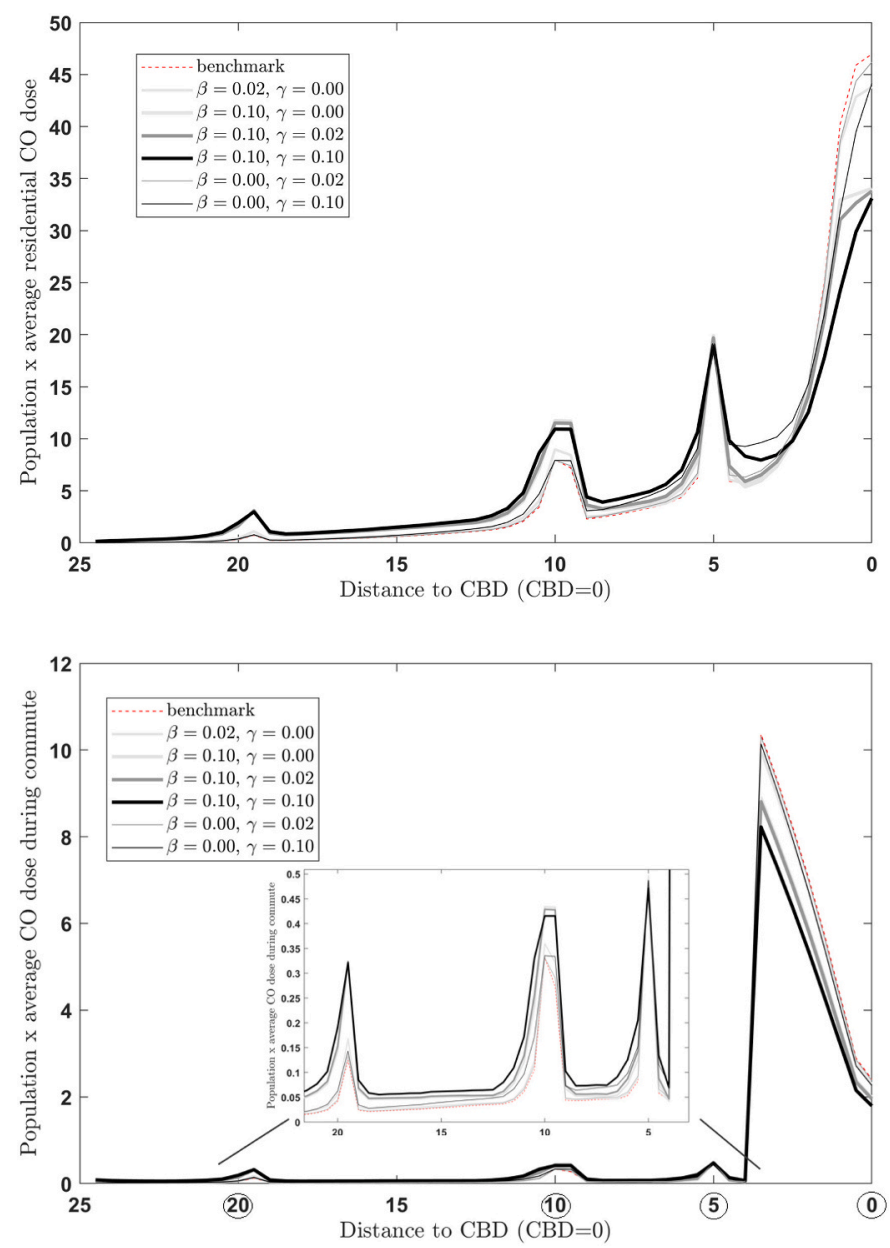

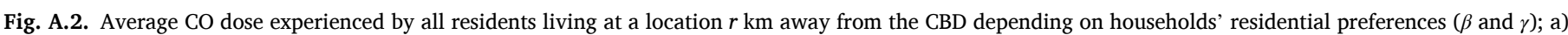
dose at a residential location $r \mathrm{~km}$ from the CBD, b) average dose during the commute of all households living at location $r$. 


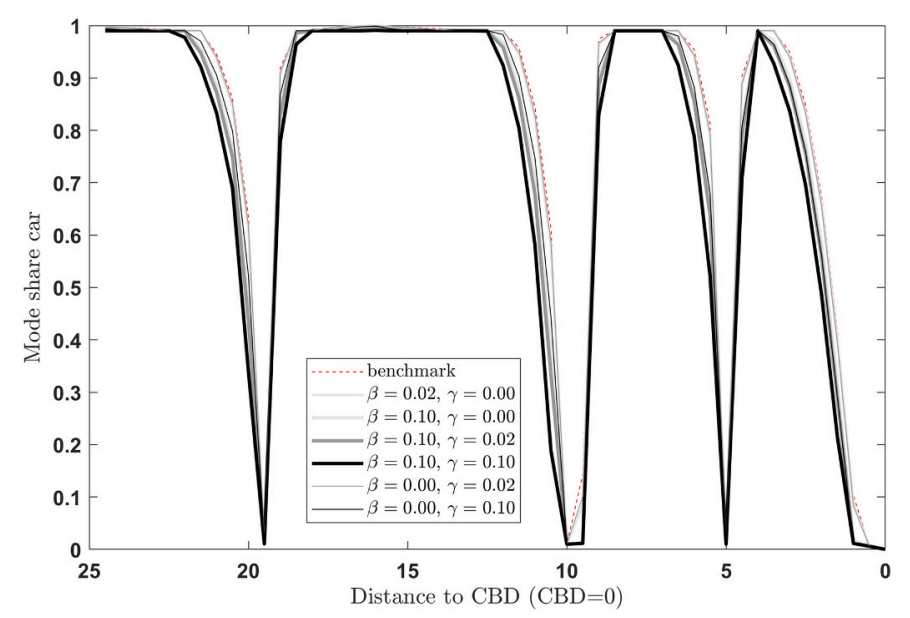

Fig. A.3. Car mode share as a function of distance to the CBD depending on households' residential preferences ( $\beta$ and $\gamma)$.

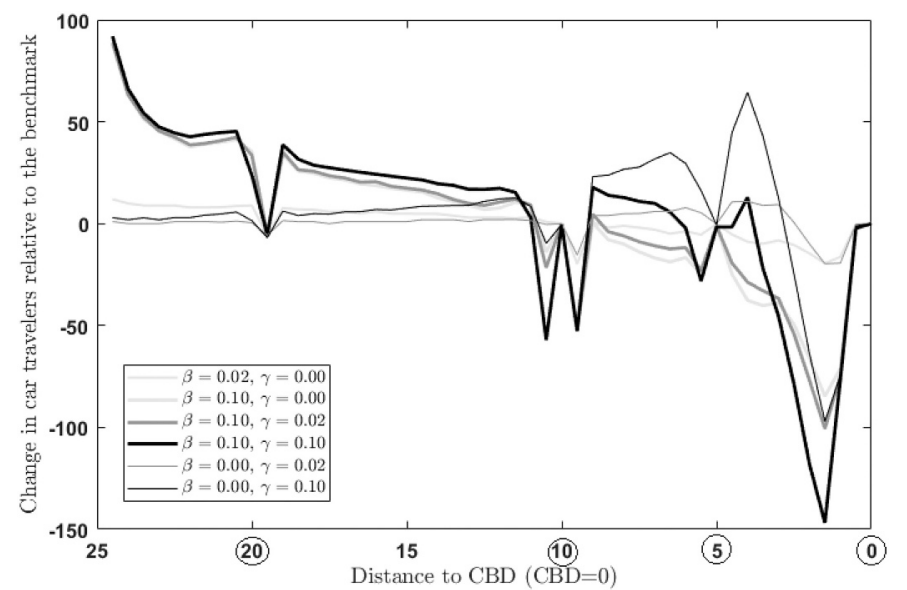

Fig. A.4. Change in the amount of car travellers relative to the benchmark scenario and as a function of distance to the CBD depending on households' residential preferences $(\beta$ and $\gamma)$.

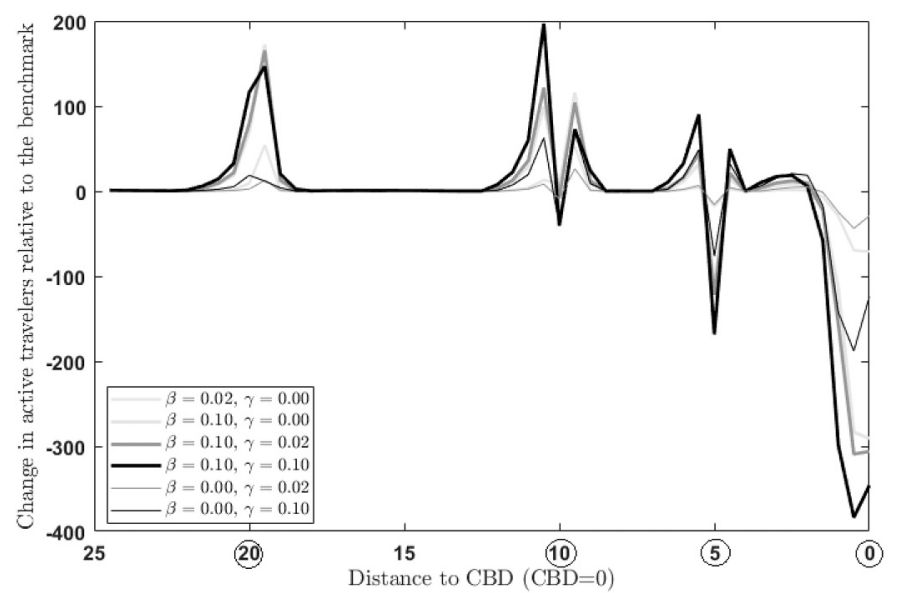

Fig. A.5. Change in the amount of train (incl. active) travellers relative to the benchmark scenario and as a function of distance to the CBD depending on households' residential preferences ( $\beta$ and $\gamma$ ). 


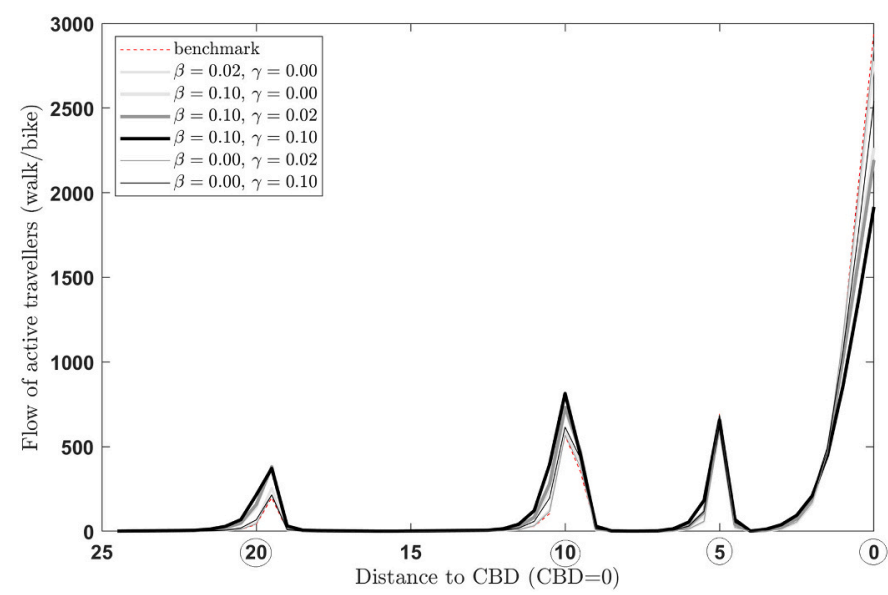

Fig. A.6. The flow of biking and walking (active transport modes) as a function of distance to the CBD depending on households' residential preferences ( $\beta$ and $\gamma$ ).

\section{References}

Affum, J., Brown, A., Chan, Y., 2003. Integrating air pollution modelling with scenario testing in road transport planning: the TRAEMS approach. Sci. Total Environ. 312, $1-14$.

Baldasano, J.M., Gonçalves, M., Soret, A., Jiménez-Guerrero, P., 2010. Air pollution impacts of speed limitation measures in large cities: the need for improving traffic data in a metropolitan area. Atmos. Environ. 44, 2997-3006.

Boogaard, H., Janssen, N., Fischer, P., Kos, G., Weijers, E., Cassee, F., van der Zee, S., de Hartog, J., Meliefste, K., Wang, M., Brunekreef, B., Hoek, G., 2012. Impact of low emission zones and local traffic policies on ambient air pollution concentrations. Sci. Total Environ. 435, 132-140.

Boogaard, H., Walker, K., Cohen, A.J., 2019. Air pollution: the emergence of a major global health risk factor. Int. Health 11, 417-421.

Borrego, C., Martins, H., Tchepel, O., Salmim, L., Monteiro, A., Miranda, A.I., 2006. How urban structure can affect city sustainability from an air quality perspective. Environ. Model Softw. 21, 461-467.

Briggs, D.J., de Hoogh, K., Morris, C., Gulliver, J., 2008. Effects of travel mode on exposures to particulate air pollution. Environ. Int. 34, 12-22.

Coria, J., Bonilla, J., Grundström, M., Pleijel, H., 2015. Air pollution dynamics and the need for temporally differentiated road pricing. Transp. Res. A Policy Pract. 75, 178-195.

de Nazelle, A., Nieuwenhuijsen, M., Anto, J., Brauer, M., Briggs, D., BraunFahrlander, C., Cavill, N., Cooper, A., Desqueyroux, H., Fruin, S., Hoek, G., Panis, L., Janssen, N., Jerrett, M., Joffe, M., Andersen, Z., van Kempen, E., Kingham, S., Kubesch, N., Leyden, K., Marshall, J., Matamala, J., Mellios, G., Mendez, M., Nassif, H., Ogilvie, D., Peiro, R., Perez, K., Rabl, A., Ragettli, M., Rodriguez, D., Rojas, D., Ruiz, P., Sallis, J., Terwoert, J., Toussaint, J.-F., Tuomisto, J., Zuurbier, M., Lebret, E., 2011. Improving health through policies that promote active travel: a review of evidence to support integrated health impact assessment. Environ. Int. 37, 766-777.

de Nazelle, A., Fruin, S., Westerdahl, D., Martinez, D., Ripoll, A., Kubesch, N., Nieuwenhuijsen, M., 2012. A travel mode comparison of commuters' exposures to air pollutants in Barcelona. Atmos. Environ. 59, 151-159.

De Ridder, K., Lefebre, F., Adriaensen, S., Arnold, U., Beckroege, W., Bronner, C., Damsgaard, O., Dostal, I., Dufek, J., Hirsch, J., IntPanis, L., Kotek, Z., Ramadier, T., Thierry, A., Vermoote, S., Wania, A., Weber, C., 2008a. Simulating the impact of urban sprawl on air quality and population exposure in the German Ruhr area. Part I: reproducing the base state. Atmos. Environ. 42, 7059-7069.

De Ridder, K., Lefebre, F., Adriaensen, S., Arnold, U., Beckroege, W., Bronner, C., Damsgaard, O., Dostal, I., Dufek, J., Hirsch, J., IntPanis, L., Kotek, Z., Ramadier, T., Thierry, A., Vermoote, S., Wania, A., Weber, C., 2008b. Simulating the impact of urban sprawl on air quality and population exposure in the German Ruhr area. Part II: development and evaluation of an urban growth scenario. Atmos. Environ. 42, 7070-7077.

Dirks, K.N., Johns, M.D., Hay, J.E., Sturman, A.P., 2002. A simple semi-empirical model for predicting missing carbon monoxide concentrations. Atmos. Environ. 36, 5953-5959.

Dirks, K.N., Johns, M.D., Hay, J.E., Sturman, A.P., 2003. A semi-empirical model for predicting the effect of changes in traffic flow patterns on carbon monoxide concentrations. Atmos. Environ. 37, 2719-2724.

Dirks, K.N., Sharma, P., Salmond, J.A., Costello, S.B., 2012. Personal exposure to air pollution for various modes of transport in Auckland, New Zealand. Open Atmosph. Sci. J. 6, 84-92.

Dons, E., Rojas-Rueda, D., Anaya-Boig, E., Avila-Palencia, I., Brand, C., Cole-Hunter, T., de Nazelle, A., Eriksson, U., Gaupp-Berghausen, M., Gerike, R., Kahlmeier, S., Laeremans, M., Mueller, N., Nawrot, T., Nieuwenhuijsen, M.J., Orjuela, J.P., Racioppi, F., Raser, E., Standaert, A., Int Panis, L., Gotschi, T., 2018. Transport mode choice and body mass index: cross-sectional and longitudinal evidence from a European-wide study. Environ. Int. 119, 109-116.

Dons, E., Laeremans, M., Orjuela, J.P., Avila-Palencia, I., de Nazelle, A., Nieuwenhuijsen, M., Van Poppel, M., Carrasco-Turigas, G., Standaert, A., De Boever, P., Nawrot, T., Int Panis, L., 2019. Transport most likely to cause air pollution peak exposures in everyday life: evidence from over 2000 days of personal monitoring. Atmos. Environ. 213, 424-432.

Gatersleben, B., Uzzell, D., 2000. The risk perception of transport-generated air pollution. IATSS Res. 24, 30-38.

Guo, J.Y., Bhat, C.R., 2004. Modifiable areal units problem or perception in modeling of residential location choice? Transp. Res. Rec. 1898, 138-147.

Hatzopoulou, M., Miller, E., 2010. Linking an activity-based travel demand model with traffic emission and dispersion models: Transport's contribution to air pollution in Toronto. Transp. Res. Part D: Transp. Environ. 15, 315-325.

HEI, 2010. Traffic-Related Air Pollution: A Critical Review of the Literature on Emissions, Exposure, and Health Effects. In: HEI Special Report 17. Panel on the Health Effects of Traffic-Related Air Pollution. Health Effects Institute, Boston, MA.

Klingen, J., Ommeren, J.V., 2020. Urban air pollution and time losses: evidence from cyclists in London. Reg. Sci. Urban Econ. 81, 1-17.

Lee, G., You, S., Ritchie, S., Saphores, J.-D., Sangkapichai, M., Jayakrishnan, R., 2009. Environmental impacts of a major freight corridor. Transp. Res. Rec. 2123, 119-128.

Lo, H.K., Luo, X.W., Siu, B.W.Y., 2006. Degradable transport network: travel time budget of travellers with heterogeneous risk aversion. Transp. Res. B Methodol. 40, 792-806.

Marshall, J., Mckone, T., Deakin, E., Nazaroff, W., 2005. Inhalation of motor vehicle emissions: effects of urban population and land area. Atmos. Environ. 39, 283-295.

Martins, H., 2012. Urban compaction or dispersion? An air quality modelling study. Atmos. Environ. 54, 60-72.

Miller, E., 2018. Integrated urban modeling: past, present, and future. J. Transport Land Use 11, 387-399.

Mitchell, G., Namdeo, A., Milne, D., 2005. The air quality impact of cordon and distance based road user charging: an empirical study of Leeds, Uk. Atmos. Environ. 39, 6231-6242.

Namdeo, A., Mitchell, G., 2008. An empirical study of estimating vehicle emissions under cordon and distance based road user charging in Leeds, UK. Environ. Monit. Assess. 136, 45-51.

Nieuwenhuijsen, M.J., 2020. Urban and transport planning pathways to carbon neutral, liveable and healthy cities; a review of the current evidence. Environ. Int. 140.

Oja, P., Titze, S., Bauman, A., de Geus, B., Krenn, P., Reger-Nash, B., Kohlberger, T., 2011. Health benefits of cycling: a systematic review. Scand. J. Med. Sci. Sports 21, 496-509.

Ortuzar, J.D.D., Willumsen, L.G., 2001. Modelling Transport, 2nd ed. John Wiley.

Rilett, L.R., Benedek, C.M., 1994. Traffic assignment under environmental and equity objectives. Transp. Res. Rec. 1443, 92-99.

Sallis, J.F., Bull, F., Burdett, R., Frank, L.D., Griffiths, P., Giles-Corti, B., Stevenson, M., 2016. Use of science to guide city planning policy and practice: how to achieve healthy and sustainable future cities. Lancet 388, 2936-2947.

Schepers, P., Fishman, E., Beelen, R., Heinen, E., Wijnen, W., Parkin, J., 2015. The mortality impact of bicycle paths and lanes related to physical activity, air pollution exposure and road safety. J. Transp. Health 2, 460-473.

Schindler, M., Caruso, G., 2014. Urban compactness and the trade-off between air pollution emission and exposure: lessons from a spatially explicit theoretical model. Comput. Environ. Urban. Syst. 45, 13-23.

Schindler, M., Caruso, G., 2018. Emerging urban form - emerging pollution: Modelling endogenous helath and environmental effects of traffic on residential choice. Environmental and Planning B. Urban Analytics and City Science 47, 1-20.

Schindler, M., Caruso, G., 2021. Urban interventions to reduce pollution exposure and improve spatial equity. Geographical Anaysis. In press. 
Schindler, M., Caruso, G., Picard, P., 2017. Equilibrium and first-best city with endogenous exposure to local air pollution from traffic. Reg. Sci. Urban Econ. 62.

Shekarrizfard, M., Valois, M.-F., Goldberg, M., Crouse, D., Ross, N., Parent, M.-E., Yasmin, S., Hatzopoulou, M., 2015. Investigating the role of transportation models in epidemiologic studies of traffic related air pollution and health effects. Environ. Res. $140,282-291$.

Shekarrizfard, M., Minet, L., Miller, E., Yusuf, B., Weichenthal, S., Hatzopoulou, M., 2020. Influence of travel behaviour and daily mobility on exposure to traffic-related air pollution. Environ. Res. 184.

Sider, T., Alam, A., Zukari, M., Dugum, H., Goldstein, N., Eluru, N., Hatzopoulou, M., 2013. Land-use and socio-economics as determinants of traffic emissions and individual exposure to air pollution. J. Transp. Geogr. 33, 230-239.

Tennoy, A., Tonnesen, A., Gundersen, F., 2019. Effects of urban road capacity expansion - experiences from two Norwegian cases. Transp. Res. Part D: Transp. Environ. 69, 90-106.

Wang, J.Y.T., Connors, R.D., 2018. Urban growth, transport planning, air quality and health: a multi-objective spatial analysis framework for a linear monocentric city. Netw. Spat. Econ. 18, 839-874.
Wang, J.Y.T., Ehrgott, M., 2018. A three-objective user equilibrium model: time surplus maximisation under uncertainty. J. Multi-Criteria Decis. Anal. 25, 3-15.

Wang, J.Y., Dirks, K.N., Ehrgott, M., Pearce, J., Cheung, A.K., 2018. Supporting healthy route choice for commuter cyclists: the trade-off between travel time and pollutant dose. Operations Research for Health Care 19, 156-164.

Woodcock, J., Edwards, P., Tonne, C., Armstrong, B.G., Ashiru, O., Banister, D. Beevers, S., Chalabi, Z., Chowdhury, Z., Cohen, A., Franco, O.H., Haines, A., Hickman, R., Lindsay, G., Mittal, I., Mohan, D., Tiwari, G., Woodward, A., Roberts, I., 2009. Public health benefits of strategies to reduce greenhouse-gas emissions: urban land transport. Lancet 374, 1930-1943.

Woodcock, J., Givoni, M., Morgan, A., 2013. Health impact modelling of active travel visions for England and Wales using an integrated transport and health impact modelling tool (ITHIM). PLoS One 8.

You, S., Lee, G., Ritchie, S.G., Saphores, J.D., Sangkapichai, M., Ayala, R., 2010. Air pollution impacts of shifting freight from truck to rail at California's San Pedro Bay Ports. Transp. Res. Rec. 2162, 25-34. 